\title{
A new look at the nature of insect juvenile hormone with particular reference to studies carried out in the Czech Republic
}

\author{
KARel SLÁMA \\ Biology Centre of Czech Academy of Sciences, Institute of Entomology, Drnovská 507, 16100 Praha 6, Czech Republic; \\ e-mail: slama@entu.cas.cz
}

Key words. Insects, activation hormone $(\mathrm{AH})$, juvenile hormone $(\mathrm{JH})$, corpus cardiacum $(\mathrm{CC})$, corpus allatum $(\mathrm{CA})$, corpus allatum hormone (CAH), neurosecretory cells (NSC), prothoracic glands (PG), ecdysteroids (Ecd)

\begin{abstract}
This article is a comprehensive summary of the 50-year history of physiological investigations in the Czech Republic into the mode of action of the corpus allatum hormone (CAH) in insects, which is commonly known as the juvenile hormone (JH). During this period 4000 synthetic JH- mimetic bioanalogues were tested. The sesquiterpenoid epoxy-homofarnesoate (JH-I), which is generally thought to be the true $\mathrm{JH}$ of insects, is an excretory product of the male colleterial gland, not an insect hormone. There are two principal hormones produced by the insect neuroendocrine system: activation hormone $(\mathrm{AH})$ produced by neurosecretory cells in the brain and JH secreted by the corpora allata. The prothoracic glands are a subordinated target of JH, not PTTH; they are not involved in the regulation of moulting in insects. The development of larval, pupal and adult structures depends primarily on inherited instructions encoded within the genome, not on high, medium or low concentrations of JH. At the level of epidermal cells, the responses to JH are always "all-or-none" with intermediate forms mosaic mixtures of cells of previous and future developmental stages.

There are two alternative theorical explanations of the action of insect hormones. The Gilbert-Riddiford theory proposes that insect development is stimulated by a moulting hormone (ecdysone) released from the PG in response to the prothoracicotropic hormone (PTTH) from the brain. Formation of larval, pupal and adult epidermal strucures depends, respectively, on high, medium or low concentrations of JH. The alternative hormonal theory of Novák-Sláma argues that PG is not involved in the regulation of insect moults. High, medium or low concentrations of $\mathrm{JH}$ have nothing in common with the selective formation of larval, pupal or adult structural characters. The immature stages of certain insect groups undergo an autonomic (hormone independent), genetically programmed morphogenesis, which can be extended over several moulting cycles. Comparative endocrinological studies revealed several common evolutionary links between the neuroendocrine systems of insects and humans. The neurosecretory cells (NSC) in the insect brain and the NSC in the human hypothalamus are homologous as are the neurohaemal organs (CC) in insects and the neurohypophysis in humans, and the glandular CA in insects is anatomically and physiologically homologous with the human adenohypophysis. The centrally produced hormones $(\mathrm{AH}$ and $\mathrm{CAH})$ alter the transcriptional potential the cellular genome. $\mathrm{AH}$ switches on genes at the most suitable moments for initiating inherited developmental programmes; JH determines in which direction the development should proceed, i.e. larval somatic growth or morphogenesis.
\end{abstract}

\section{INTRODUCTION}

Insect endocrinology is a very competitive field of biological sciences. The old hormonal theories, proposed some 50 years ago, are conservatively presented in textbooks on insect physiology (Nijhout, 1994; Nation, 2002; Klowden, 2007) and now on the Internet, without mentioning new, alternative endocrinological data. The problem started when the newly discovered, nontoxic bioanalogues of insect JH (juvenoids) were massively promoted as a possible replacement for the neurotoxic insecticides used to control insect pests (review by Sláma \& Williams, 1966a; Williams \& Robbins, 1968). This proved attractive to a number of ambitious industrial chemists, who wanted to contribute to this new generation of pesticides (Law et al., 1966; Cruickshank, 1971; Schwarz et al., 1974; Dorn et al., 1981; Karrer \& Farooq, 1981; Henrick, 1995; see review by Sláma et al., 1974).

In the mid 1960s, an outstanding chemist, Peter Karlson isolated a moult-stimulating compound, ecdysone, from silkworm pupae, which was assumed to stimulate the shedding the old cuticle (ecdysis). Following the theory of Williams (1952), Karlson assumed that ecdysone was produced by the PG (Karlson, 1966, 1971; Karlson \& Sekeris, 1966). The definition of ecdysone as the moulting hormone produced by the PG became the leading concept in insect endocrinology for 50 years (review by Koolman, 1989; Lafont et al., 2012). Stimulation of precocious cuticle apolysis by ecdysone inspired extensive research on morphological, physiological and biochemical effects of ecdysteroids (Ecd) on insect development. The biological status of Ecd as insect hormones was safeguarded for several decades by a group of biochemists ("ecdysonists"; see Gilbert, 1989; review by Koolman, 1989) and molecular biologists (Riddiford, 1985; Gilbert, 2012; Jindra et al., 2013).

Soon after the chemical structure of ecdysone was determined, plant physiologists almost immediately announced finding large amounts of ecdysone-like, polyhydroxylated 6-keto, 7-dehydro derivatives of cholesterol in a number of lower and higher plants (review by Sláma, 1979; Lafont et al., 2012). The vitamin-like, widely distributed occurrence of Ecd in plants did not conform with the animal hormone 
status of ecdysone. It is true that plants contain numerous hormonal mimics of estrogenic hormones (phytoestrogens) and bioanalogues of insect $\mathrm{JH}$, but never produce animal hormones (Sláma, 2013).

The chemists' view of the hormonal status of "phytoecdysones" was complicated due to the confusion over the fact that the silkworm pupae used by P. Karlson to isolate ecdysone do not have a PG (Sláma, 1980b, 1988). Moreover, a similar amount of Ecd to that obtained by P. Karlson from $500 \mathrm{~kg}$ of silkworm pupae, was obtained from $1 \mathrm{~g}$ of the fern Polypodium by Jizba et al. (1967). Further inconsistencies in the biological status of Ecd were revealed when the common endogenous peaks of Ecd in insect haemolymph were produced in tissue and organs other than the PG (Hsiao et al., 1975; Delbecque \& Sláma, 1980). Larvae deprived of their PG are able to moult several times and metamorphose successfuly into normal pupae and adults (Sláma, 1983). The astonishing, vitamin $\mathrm{D}_{6}$-like pharmacological effects of Ecd in vertebrates and its strong anabolic effects on humans (Sláma, 1993; Sláma \& Lafont, $1995)$ provide indirect evidence that these vitamin-like, essential natural products are biologically and pharmacologically far more important than a hormone produced by the tiny insect $\mathrm{PG}$.

Ironically, the brain-PG theory of Williams (1952), which led Karlson to define ecdysone as the PG hormone, was later abandoned by its creator (Williams, 1987), when he discovered that the disintegrating pupal intestine, not the PG, sequesters a large amount of Ecd into the circulating haemolymph in Manduca. Unfortunately, contemporary biochemists and molecular biologists still ignore the confession of Williams (cf. Riddiford, 2012; Gilbert, 2012; Jindra et al., 2013). They also neglect the PG-independent biological and pharmacological effects of Ecd (Sláma, 1983, 1993, 2013) and seriously underestimate the physiologically important, homeostatic role of Ecd in insect ecdysis and oviposition (Sláma, 1980a), and ignore that endogenous Ecd peaks always occur at the moments of the minimum total body metabolism (Sláma, 1982) and the theory of sterol reutilisation of Ecd proposed by Sláma (1998). This theory claims that the nonfeeding insect stages are unable to synthesize the sterolic nucleus de novo. They reutilize the structurally bound polyhydroxylated, 6-keto, 7-dehydrocholesterol (Ecd) that is obtained from food and later liberated from old, disintegrating larval tissues.

The story of the insect brain hormone, which is referred to by the pioneers of insect endocrinology as the activation hormone (AH) (Wigglesworth, 1954, 1970; Novák, 1966, 1975), is closely linked with JH. The history of insect hormones actually started in 1917, when Kopeć demonstrated that the brain hormone stimulated development in Lepidoptera (Lymantria dispar; review by Kopeć, 1922). Originally, Kopeć experimented with a Coleopteran species (Tenebrio molitor) and could find no evidence that a hormone stimulated development. This fact was later confirmed by Janda (1933) and other endocrinologists (Hsiao et al., 1975). The findings of Kopeć were extended by Wigglesworth's $(1935,1936)$ studies on larvae and adults of Rhodnius prolixus and by Bounhiol (1938), who described the action of $\mathrm{AH}$ in caterpillars of the silkworm, Bombyx mori. However, the most elegant demonstration of the brain hormone (AH) was provided by Williams (see Williams, 1952 for a review). In principle, he induced development in diapausing pupae of Cecropia silkworms by transplantating into them the active brains of previously chilled and developing pupae. At the time when Williams did these experiments it was unknown that the brain NSC produced neuropeptides. The "brain hormone" of Williams, or AH of Wigglesworth and Novák, were based on cytological investigations of the so called, Gomori positive proteinic materials rich in S-S- or SH-bonds (review by Highnam \& Hill, 1969; Raabe, 1982).

At present, our knowledge of the chemical structures of insect brain hormone is much more advanced due to neuropeptides isolated from the CC (Žitňan et al., 2002; Antonova et al., 2012; Smith \& Rybczynski, 2012; Žitňan \& Adams, 2012; Schooley et al., 2012). Acording to Nässel (2002), there are 23 genes encoding for neuropeptide precursors in the Drosophila genome and an additional seven genes predicted to encode insulin-like peptides or neuropeptides. Geary \& Maule (2010) describe approximately three dozen neuropeptides whose physiological functions in the insect body are not fully understood. In other words, a century after the discovery of Kopeć, several dozens of neuropeptides are known, but nobody knows which of them might be the true brain hormone or AH investigated by Kopeć, Wigglesworth, Williams and Novák (see review by Novák, 1966, 1975).

The history of $\mathrm{JH}$ is a more complicated physiological story. The first extracts with JH activity were discovered by Williams in 1947 in lipid extracts of abdomens of adult male Cecropia silkworms (Williams, 1952 for a review). Obviously, Williams was unaware at that time of the widespread JH-mimetic activity of lipid extracts. He did not know that there were several thousand synthetic compounds (juvenoids) all perfectly imitating the effects of insect JH (Sláma et al., 1974; Sláma, 1999). Soon after Williams published his findings (Williams, 1947), JHactive lipid extracts were recorded not only from insects but also other biological materials. For instance, they were recorded from crustaceans and other invertebrates (Schneiderman \& Gilbert, 1958), adrenal cortex of vertebrates (Gilbert \& Schneiderman, 1958), thymus, human placenta and other vertebrate organs (Williams et al., 1959), microorganisms and plants (Schneiderman et al., 1960) and also from other but not all insect species (Gilbert \& Schneiderman, 1961). Curiously, the lipid extracts prepared from the female abdomens of Cecropia silkworms were inactive, as were the extracts prepared from larvae or adult males of several other lepidopteran species (Gilbert \& Schneiderman, 1961).

The first JH-active compound of known chemical structure was farnesol, a sesquiterpenoid alcohol in the lipid extracts of yeast and excrement of the beetle Tenebrio molitor (Karlson \& Schmialek, 1959; Schmialek, 1961). This finding immediately attracted the attention of chemists into the 
field of isoprenoids. Schmialek (1963) analyzed lipid extracts of Cecropia and identified the JH-active compound as 3,7,11-trimethyl-2,6,10-tridecatrien-1-ol, which cochromatographed with farnesol. Later on, Röller \& Bjerke (1965) and Röller et al. (1967) purified the lipid extracts from Cecropia and identified the most active compound as the closely related, methyl 10,11-epoxy, 7-ethyl-3,11dimethyl-2,6-tridecadienoate (Röller et al., 1967, 1969), which became known as JH-I. Since then, this epoxy-homofarnesoate ester has been generally believed to be the true CA hormone of insects and is still so advocated by biochemists and molecular biologists (Gilbert, 2012; Goodman \& Cusson, 2012; Devillers, 2013a; Riddiford, 2012; Jindra et al., 2013; Smýkal et al., 2014b).

Williams (1963) believed that the JH-active principle in lipid extracts of Cecropia was made within the CA, before it was translocated and deposited in male abdomens. Later the JH-active materials were found in the male sexual (colleterial) glands (Meyer et al., 1968; Shirk et al., 1976). The chemical idea of separate secretion and accumulation of an animal hormone in the abdomen was questioned by physiologists. Nevertheless, the biochemists expected that the hormone from the CA would be secreted in a biologically inactive form such as the more polar homofarnesenic acid. It is thought that this acid is esterified and converted into the biologically active homofarnesoate ester (JH-I) in the colleterial gland (Peter et al., 1979, 1981; Shirk et al., 1983; Goodman \& Granger, 2005). The process of esterification of farnesenic acid by O-methyltransferase enzymes in homogenates of CA was a fashionable topic of JH biosynthesis for many years (reviews by Hui et al., 2013).

It has already been mentioned that the search for synthetic bioanalogues of JH from 1970-1990, revealed more than 4000 "pseudojuvenile", biological mimics of JH (juvenoids) (reviews by Sláma et al., 1974; Sláma, 1985, 1999). Most of these man-made JH analogues do not contain an ester group and a large number of them are not even isoprenoids. There are some peptidic juvenoids that surpass the hormonal activity of JH-I by more than a hundred thousand-fold (Sláma et al., 1974). The relatively low biological activity of JH-I further increased the doubts about JH-I and CAH being the same chemical (Sláma, 1961, 1962; Novák, 1966). These doubts were accentuated by the common physiological wisdom (Pflugfelder, 1958; Novák, 1975) that CA glands of nonfeeding adult stages of insects, like adult silkworms, never produce this hormone. In spite of the extensive data in the literature, Yamashita et al. (1961) and Banno \& Akai (1988) found that the CA of adult silkworms were virtually inactive. This prompted the reinvestigation of the distribution of JH-I in Cecropia silkworms, using modern methods of chromatography/mass spectrometry (Paroulek \& Sláma, 2014), which revealed that the homofarnesoate ester $(\mathrm{JH}-\mathrm{I})$ is not made in the CA, but biosynthesized, together with the related sesquiterpenoid Vitamin E ( $\alpha$-tocopherol), exclusively in exocrine, not endocrine, accessory sexual (colleterial) glands of Cecropia males.
At the time when Wigglesworth $(1935,1936)$ published the results of his endocrinological experiments on the effects JH on Rhodnius, outstanding comparative physiological studies on animal hormones, indicating some common evolutionary links between the invertebrate and the human neuroendocrine systems were also published (Scharrer \& Scharrer, 1937, 1944; Hanström, 1939). These studies were partly discontinued during World War II. As younger generations of scientists do not read the old literature, it may be useful to remind the reader of some of the very old, but crucial endocrinological publications by Hannström (1939), Scharrer \& Scharrer (1944), Wigglesworth (1954, 1970), Pflugfelder (1958), Novák (1966), Highnam \& Hill (1969), Sláma et al. (1974), Raabe (1982) and confront the new interpretations of insect hormone action (Jindra et al., 2013; Smýkal et al., 2014a, b) based on the results of some of the studies carried out over the past 50 years (Sláma et al., 1974; Sláma, 1985, 1999). Insect endocrinology changed substantially during this time. The laborious transplantations of glands was replaced by biochemical methods based on the pipetting of liquids between test tubes, and more important topic than hormones became the receptors.

\section{MATERIAL AND METHODS}

The material and methods used in this study are mostly described in previous publications. In addition, extirpations of NSC from the brain, and removal of CA and CC from Pyrrhocoris apterus were made in Ringer solution, using specimens immobilized by submersion in water (Sláma, 1964a, b). The experimental procedures related to ligaturing and transplantations of the endocrine glands of Galleria mellonella and Dermestes vulpinus are also previously described by Sláma et al. (1974), Sláma (1975). The methods used in the scanning EM of the epidermal cuticular mosaics of the intermediates induced by JH can be found in Sláma \& Weyda (1997). The methods used to determine the concentration of Ecd in D. vulpinus are described in Delbecque \& Sláma (1980) and the chromatographic/mass spectrometric methods used for the determination of JH-I in adult Hyalophora cecropia are described by Paroulek \& Sláma (2014).

\section{RESULTS AND DISCUSSION}

\section{The effect of JH on the epidernal cells in larval wing lobes of Pyrrhocoris}

Wigglesworth (1940, 1954, 1970) beautifully describes the cytological changes that occur in the epidermal cells of Rhodnius. He records the role of CA hormone as an inhibitor of metamorphosis (the "inhibitory hormone"; Wigglesworth, 1936, 1940). He also noticed that the inhibition of metamorphosis did not include an inhibition of cell differentiation. In young larval instars with an active CA, there were always some cells that differentiated de novo into dermal glands or larval bristles. In addition, Wigglesworth (1970) noticed that mitotic divisions occasionally resulted in the production of more daughter cells than was required. Some daughter cells were thus programmed to die and leave space for differentiating neighbouring cells.

When Wigglesworth summarised his JH studies on Rhodnius (Wigglesworth, 1962), we studied the effects of 


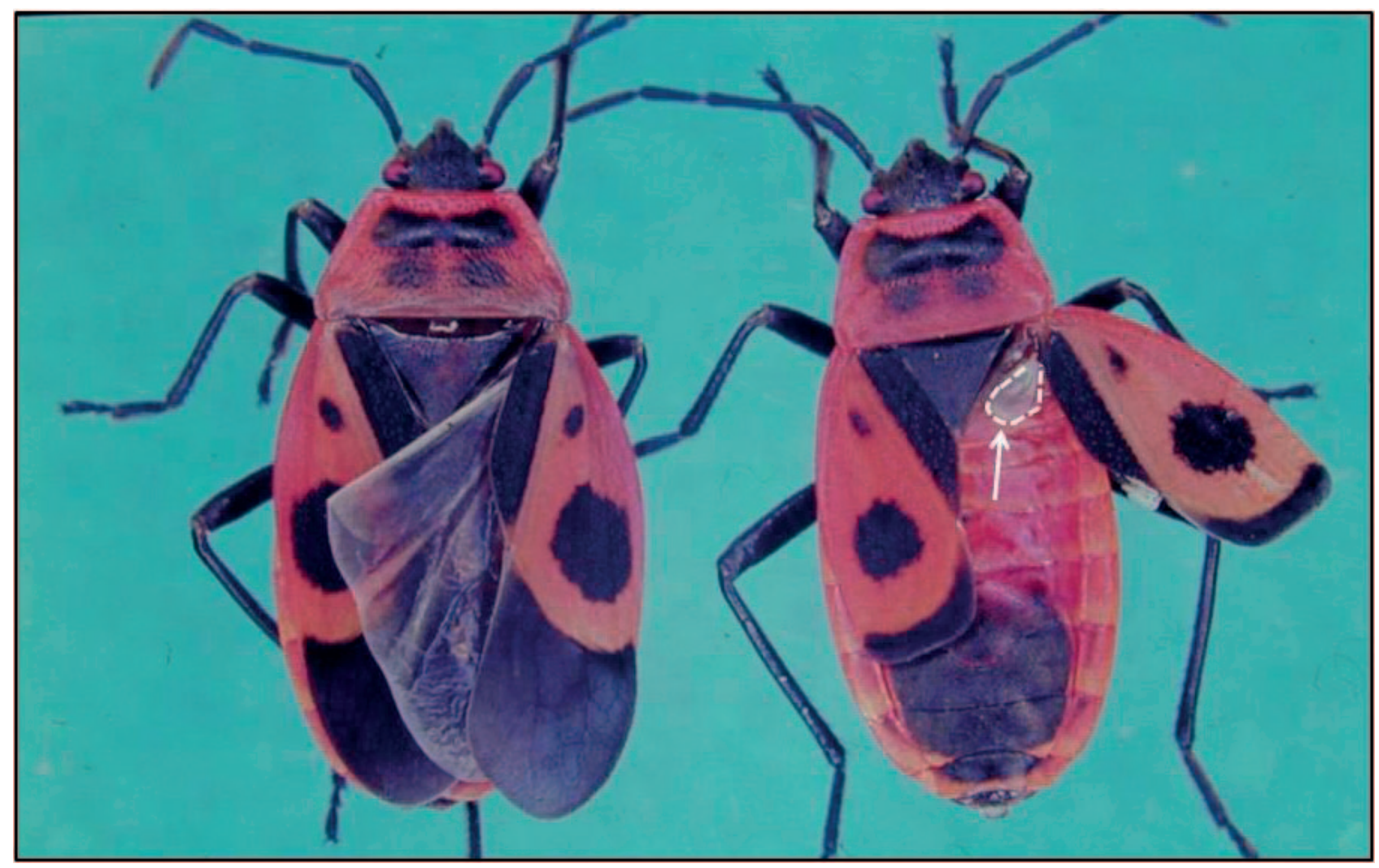

Fig. 1. Adult females of Pyrrhocoris apterus: fore wings of macropterous mutant on the left have large membraneous areas and fully developed hind wings whereas the adult female on the right is the wild type with small fore wings and rudimentary hind wings, indicated by an arrow.

removing and transplanting the CA in the European fire bug, Pyrrhocoris apterus (Novák \& Sláma, 1960; Novák \& Červenková, 1960). At that time, ecdysone was still unknown and the brain hormone of Kopeć and Williams was assumed to be the neurohormone "D" of M. Gersch (Pflugfelder, 1958; Novák, 1959). In Pyrrhocoris, unlike in Rhodnius, there is wing polymorphism, which is depicted in Fig. 1. The macropterous mutants have long wings with large terminal membranes and fully developed hind wings. In the wild type (apterus) the membanous parts of the fore wings are considerably reduced in area and the hind wings rudimentary (Fig. 1, arrow). The great selective advantage of the apterus phenotypic form is that the females lack indirect wing musculature and have larger ovaries with more eggs, which occupy the space occupied by thoracic flight musculature in macropterus individuals. The apterus form is obviously unable to fly, but the females lay substantially more eggs. It is important to know that the wing dimorphism depicted in Fig. 1 is determined genetically, not by the action of JH. A high or low concentration of JH does not determine how many larval cells will die or survive and differentiate into the future wings. The fate of these cells is determinded by an inherited programme coded by the chromosomal genes of each cell (hypothetical Gradientfactor according to Novák, 1959 ?). The review of Sláma et al. (1974) presents the pefect morphological patterns and physiological conditions of larval-adult intermediates (adultoids) produced by JH in Pyrrhocoris. Quite recently, a group of molecular biologists (Smýkal et al., 2014b) reported the induction of precocious adultoids in this species, by manipulation of the Met receptor. Similarly, a number of allatectomies of the penultimate larval instars of Pyrrhocoris precociously moulted into small adults or adultoids the wings and tarsal segments of which were subjected to a detailed morphological analysis (Sláma, 1964a). Unfortunately, the precocious adultoids of Pyrrhocoris used by Jindra et al. (2013) and Smýkal et al. (2014b) for illustrating the antijuvenile effects of Met and injections of RNAi, are not true precocious adults or adultoids.

Fig. 2 is a camera lucida drawing of the wing-lobe epidermal cells, during the development of the giant, supernumerary larval instars caused by implanting an active CA. Under the influence of $\mathrm{JH}$, the epidermal cells of both the fore and hind wing lobes enlarged half way through the instar, detached from the old cuticle and underwent mitotic divisions. Towards the end of the supernumerary larval instar (duration 5 days), the daughter cells secreted a similar larval wing lobe cuticle (Fig. 2C).

In the absence of $\mathrm{JH}$, during the normal last larval instar, or after allatectomy of the penultimte larval instar, the wing-lobe epidermal cells quickly detach from the old larval cuticle, just a few hours after the larva started to feed (Fig. 3A, B). The development associated with apolysis can be suspended by starvation, which inhibits the release of $\mathrm{AH}$ from the brain. After the initiation of development in the absence of JH (Fig. 3B), certain of the developing 


\section{Larval $\rightarrow$ larval development in presence of $\mathrm{JH} ; 5$ days}

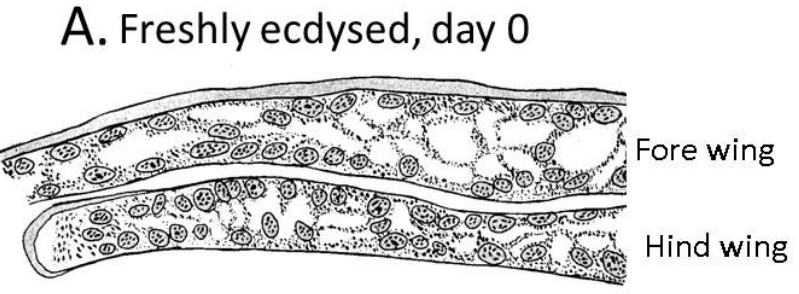

B. In the middle, day 2

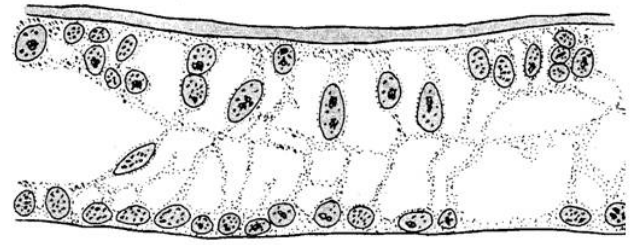

Fore wing

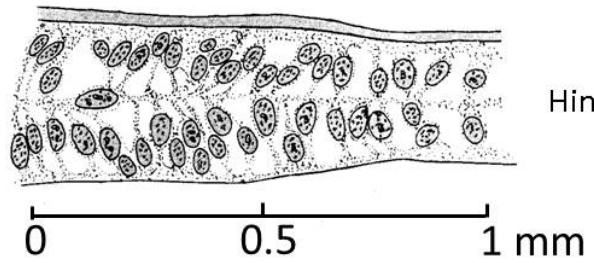

\section{Before larval ecdysis, day 4}
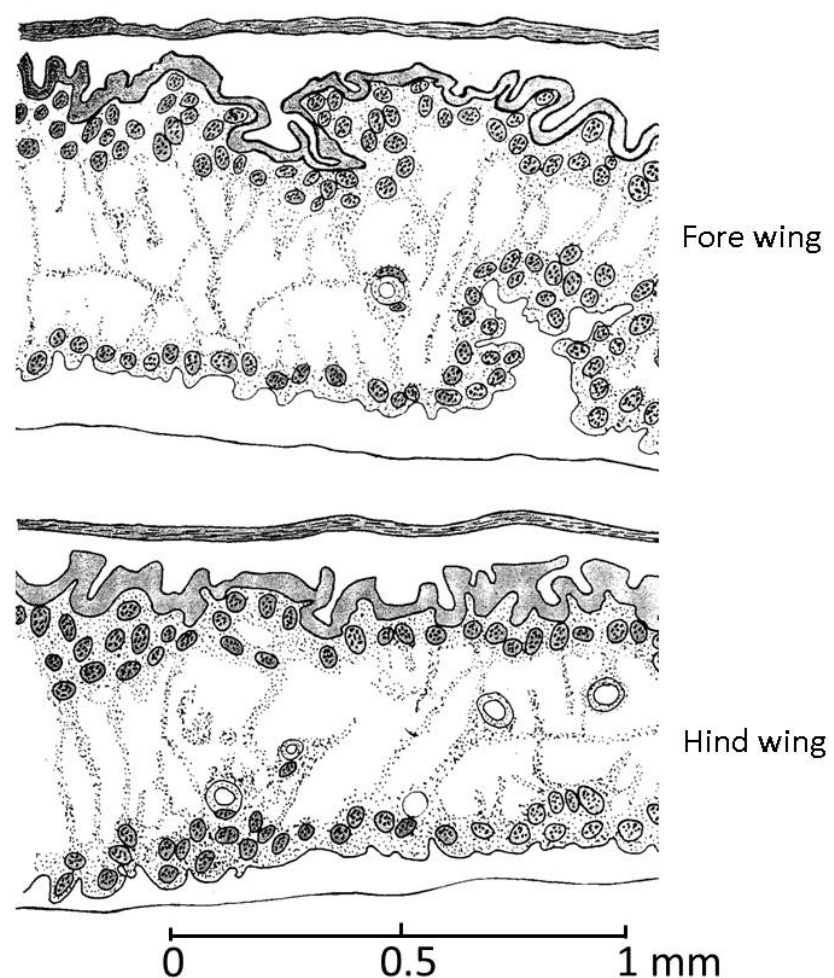

Fig. 2. Schematic camera lucida drawings of the cytological changes that occur in epidermal cells in the wing lobes during supernumerary larval development, induced by implantation of an active corpus allatum into freshly moulted 5th instar larvae of Pyrrhocoris apterus (from Sláma, 1964a).

epidermal cells in the fore wing (flying membranes) and almost all the cells in the hind wing, disintegrate and die. The programmed cell death stimulated by $\mathrm{AH}$ in the absence of $\mathrm{JH}$ is associated with the appearance of special "chromatic droplets" (see Fig. 3B, in the hind wing), which are described and mentioned many times by Wigglesworth (review by Wigglesworth, 1970). The most intensive cell death obviously occurred in the hind wing lobe, where only a few cells survive and make up the small rudiment marked in Fig. 1 by an arrow. In the fore wing, there are two highly proliferated layers of epidermal cells folded together within the enlarged space of the wing lobe (Fig. 3C). Cytologically, the newly formed adult cuticle can be distinguished from the smooth larval cuticle by small denticles that prevent the adult wings sticking together. During prolonged juvenoid assays thousands of giant supernumerary larvae or larval-adult intermediates were obtained, which never moulted in spite of excessive dosages of JH-active compounds. This indicates that all the immature cells that were previously competent to moult died during the larval-adult transformation.

The effects of JH illustrated in Figs 2 and 3 have several endocrinological implications: (1) Development, with or without effective concentrations of $\mathrm{JH}$, was initiated by the central neuroendocrine system (AH from NSC of the brain) in response to feeding, not by the PG or Ecd, which are not present in the feeding stages of insects (Sláma, 1964a); (2) In the presence of $\mathrm{JH}$ wing lobe cells grow, detach from the cuticle, mitotically divide and produce a smooth larval cuticle; (3) In the absence of $\mathrm{JH}$, however, some cells are programmed to proliferate while others, often neighbouring cells disintegrate and die; (4) Evidently, the qualitatively different responses of wing lobe epidermal cells to $\mathrm{AH}$ (either to die or form adult structures in absence of $\mathrm{JH}$ ), are determined by genes on the chromosomes of the target cells, not by a centrally produced hormone; (5) The selective advantage of the control of development by the central neuroendocrine system depends on synchronization of developmental features with favourable environmental conditions (availability of food and water, suitable temperature and photoperiod). The morphogenetic fate of the wing lobe cells of Pyrrhocoris are a good example of the electrical switch-like principle (Sláma, 1985) and epigenetic function of centrally produced hormones (Sláma, 2013).

When synthetic JH analogues became available, CA transplantations were replaced by topically treating the last instar larvae with $\mathrm{JH}$ analogues (review by Sláma et al., 1974). During the search for new JH-active materials, hundreds of larval-adult intermediates of Pyrrhocoris were produced that exhibited mosaics of epidermal structures composed of red larval cells (with transparent cuticle) and adult cells with black melanin pigmented cuticles. These 


\section{Larval $\rightarrow$ adult development in absence of $\mathrm{JH} ; 7$ days}

A. Freshly ecdysed, day 0

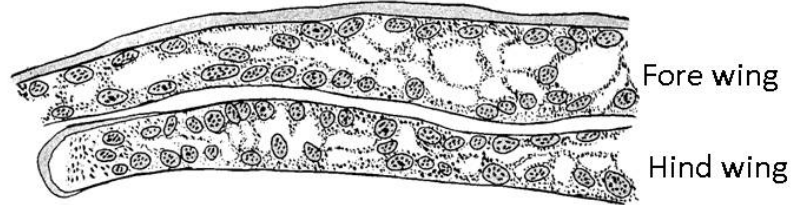

B. Day-2
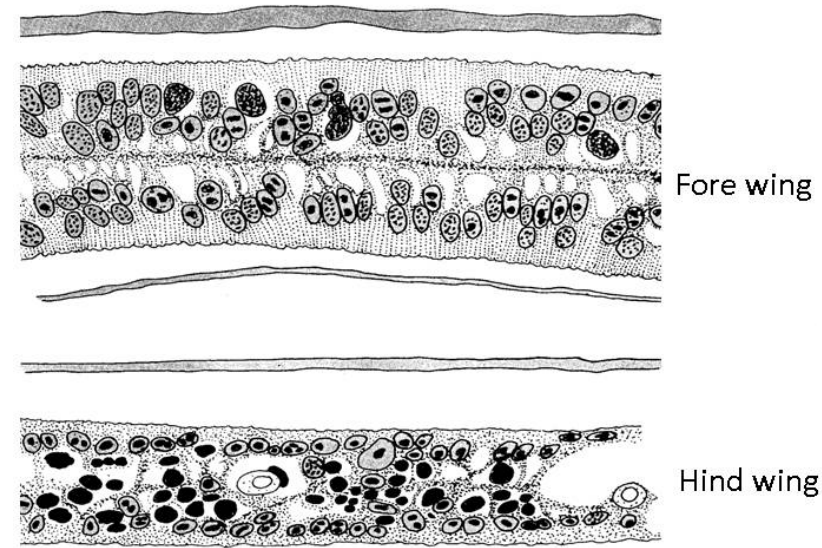

Hind wing

\section{Before adult ecdysis, day 6}

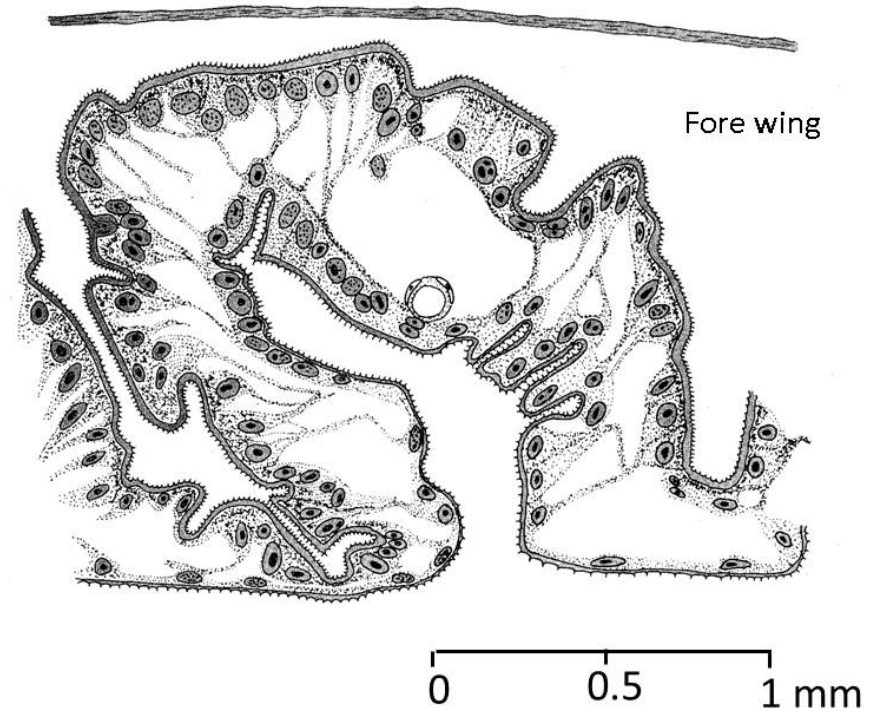

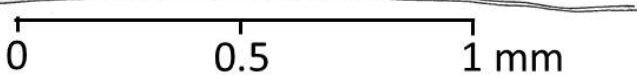

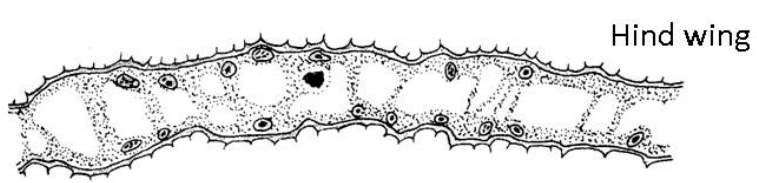

Fig. 3. Schematic camera lucida drawings of the cytological changes that occur in epidermal cells in the wing lobes during normal larval-adult metamorphosis of the last larval instar of Pyrrhocoris apterus (from Sláma, 1964a).

intermediates always consisted of a mosaic of old larval and new adult morphological patterns. Based on the idiom "tertium non datur", it is concluded that the action of $\mathrm{JH}$ at the level of individual cells proceeds according to the "all-or-none" rule (Sláma et al., 1974). Theoretically, all epidermal cells that are stimulated by AH to develop in either one $(+\mathrm{JH})$ or the other $(-\mathrm{JH})$ direction, should become virtually insensitive to further hormonal signals, until they reach the ultimate morphogenetic destination.

The "all or none" responses of epidermal cells to JH was challenged by Sehnal and his co-workers (Willis, 2007; Willis et al., 1982; Sehnal, 1984), who strongly supported the quantitative, high-medium-low JH concentration theory of Piepho. They report observing special "composite cells" or "composite cuticles", with the combined characters of both the previous and the next developmental stages. They give examples of larval cells with pupal pigmentation, which was then an unknown feature in insect ontogeny. The descriptions of the ambivalent, half larva half pupa "composite" epidermal cells (Willis et al., 1982) were based on light microscopy, which is unsuitable for an unequivocal distinction of the cuticular patterns. Reinvestigation of the possible existence of the ambivalent "composite" cuticles using advaned methods of scanning EM (Sláma \& Weyda, 1997) confirmed the "all-or-none" rule of JH action on epidermal cells, both in Exopterygota (Pyrrhocoris) and Endopterygota (Galleria, Manduca). By way of illustration, Fig. 4 shows a mosaic of smooth larval cells with larval bristles interspersed with adult wing cells characterized by small denticles that prevent adult wings adherring to one another. According to Sláma \& Weyda (1997), the scanning EM method can distinguish larval, pupal and adult epidermal architecture in exopterygote and endopterygote insects.

The principal reason for mentioning the mosaic or composite distribution of epidermal cells in intermediate forms of insects (Sehnal, 1984; Sláma \& Weyda, 1997; Willis, 2007 ) is to provide experimental evidence that the hormonal stimuli initiating larval moults $(+\mathrm{JH})$ or metamorphosis $(-\mathrm{JH})$ are decided in the central neuroendocrine system $(\mathrm{AH})$, not by peripheral genes (Met). Moreover, these important hormones are secreted during periods of intensive feeding, when ecdysone and other Ecds are virtually absent (Sláma, 1982, 1988, 1998). This indicates that insects do not need a special moulting hormone, except for the myogenic neuropeptides that trigger the neuromuscular act of ecdysis. In other words, stimulation of growth and differentiation by $\mathrm{AH}$ does not require ecdysone or Ecd, which appear to be consequences, not the cause of the developmental process. In the light of these facts and the conclusions of Sláma (2013), the widespread acceptance of the necessity of PTTH and a special moulting hormone secreted by the PG appear purely speculative. 


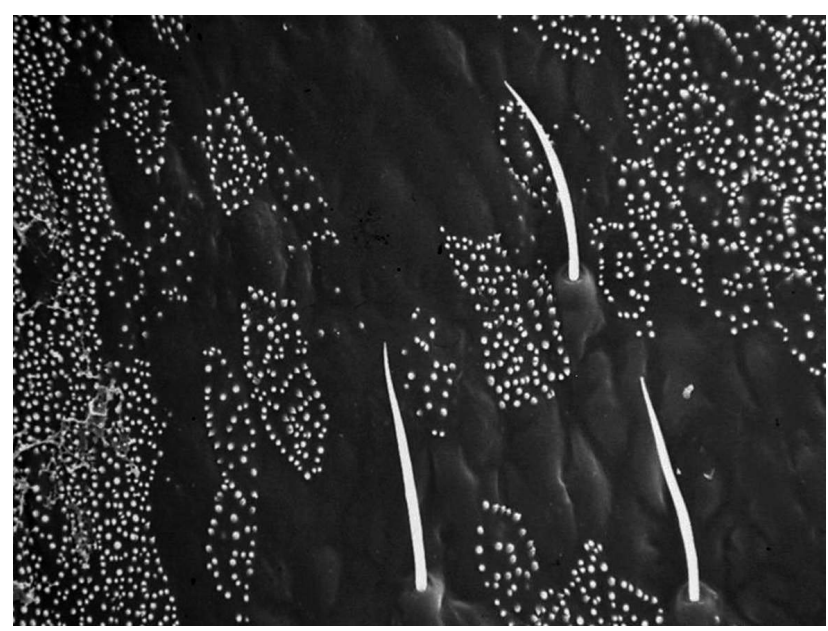

Fig. 4. Scanning EM photograph of the fore wing cuticle of a larval-adult intermediate produced by treating Pyrrhocoris apterus with a juvenoid. Mosaic distribution of larval wing lobe cells with smooth cuticle and larval bristles, interspersed with adult wing cells with white denticles that prevent the wings sticking together (from Sláma \& Weyda, 1997).

In connexion with the assays of the $\mathrm{JH}$ action of farnesol and lipid extracts from Cecropia there are false, JH-mimetic or pseudojuvenilizing effects of various structurally unrelated chemical compounds (Sláma, 1962). In Pyrrhocoris apterus, the effects of these mimetic materials (free fatty acids, protein denaturants, antimetabolites, antimitotic agents) are best recognised in the formation of adult wings (Sláma, 1962). Recently, however, Konopová et al. (2011) and Jindra et al. (2013) describe the induction of JH-like and anti-JH-like effects in Pyrrhocoris resulting from injections of RNAi and manipulations of the Met (methoprene tolerant gene). They present a picture of a precociously moulted, larval-adult intermediate that emerged prematurely from a penultimate larval instar (N5 adultoid in Fig. 3; Jindra et al., 2013). This, however, is not an adultoid, but a trivial, slightly distorted small adult that moulted from a normal 5th instar larva based on the number of tarsal segments. The wings show typical pseudojuvenile effects that could be caused by traces of protein denaturants and other chemicals (Sláma, 1962). The fact that Jindra et al. (2013) provide a picture of a crippled adult rather than an adultoid indicates that they may have never seen a precociously moulted adultoid of Pyrrhocoris. This is worrying, because the main support for a Met gene and Met receptor (Jindra, 2014) depends on the induction of premature pupal or adult forms.

\section{Hormonal control of growth and respiratory metabolism in adult females}

The best stage for studying insect hormones are adult insects, which avoids the complications associated with PTTH and the moulting hormone secreted by the PG. Adult females of $P$. apterus exhibit distinct cycles of reproduction separated by ovipositions, which are similar to larval moults and ecdyses. The cycles are regulated by the interaction between two centrally produced hormones (Sláma, 1964b). These are: (a) AH produced by the NSC in the brain and released from the $\mathrm{CC}$; and (b) JH produced by active CA (reviews by Pflugfelder, 1958; Novák, 1966, 1975; Engelman, 1970). The first results on the role of CA in adult females were obtained by Wigglesworth (1936, 1970) for Rhodnius by parabioses. Unlike Rhodnius, however, Pyrrhocoris has only one, fused and relatively large corpus allatum, which can be removed from living bugs. It is also possible to remove the individual NS cells from the brain or selectively remove the $\mathrm{CC}$ or ovaries of this species, with negligible mortality (Sláma, 1964b). These "classical" endocrinological manoeuvres were used 50 years ago for studying the effects of hormones on growth and respiratory metabolism $\left(\mathrm{O}_{2}\right.$ consumption). The results of this study are schematically outlined in Fig. 5.

That is 50 years ago, it was known that the effects of endocrine glands on growth are closely linked with changes in respiratory metabolism. There are 3 categories of hormonal responses: 1 . Periodically repeated cycles of relatively high metabolic intensity, associated with vitellogenesis and the formation of ripe eggs in normal females. These cycles are separated by the periodical laying of 60 to 80 eggs, which is the result of a physiological interplay between the AH from NSC in the brain (oviposition, feeding) and $\mathrm{JH}$ from the $\mathrm{CA}$ (amitotic divisions of the ovarian follicle cells, vitellogenesis). The respiratory metabolism of reproducing females oscillated between a maximum at the peaks in ovary development $\left(1200 \mu \mathrm{l} \mathrm{O}_{2} / \mathrm{g} / \mathrm{h}\right)$ and minimum at the time of the ovipositions $(700 \mu \mathrm{l} \mathrm{O} / \mathrm{g} / \mathrm{h}) ; 2$. The second category of the hormonal effects on reproduction involved allatectomised or ovaryectomised females with arrested ovarian growth or no ovaries (ovaryectomy). These females usually fed until their bodies became highly hypertrophic. The respiratory metabolism of those females with arrested ovarian growth revealed intermediate rates of $\mathrm{O}_{2}$ consumption $\left(700 \mu \mathrm{l}\right.$ of $\left.\mathrm{O}_{2} / \mathrm{g} / \mathrm{h}\right) ; 3$. The third category in Fig. 5, are the females with all their endocrine centers removed (extirpated NSC from the brain, removed CC plus CA) or females and males in physiologically inhibted hormonal activity (diapause). These females with inhibited ovarian growth accepted food only sporadically and digested only fat or carbohydrate, not protein. The $\mathrm{O}_{2}$ consumption rates of both diapausing females and all males indicate a basal metabolic rate $\left(400 \mu \mathrm{l}\right.$ of $\left.\mathrm{O}_{2} / \mathrm{g} / \mathrm{h}\right)$, irrespective of their hormonal treatments (see Fig. 5).

The above results indicate that, irrespective of their chemical nature, each of the two most important hormones (AH and $\mathrm{JH}$ ) act on their own and target specific tissues and organs. The exclusive physiological targets of $\mathrm{JH}$ are in females the ovarian follicle cells and accessory sexual gland cells (Jedlička et al., 2009). The targets of AH are a complex of tissues or organs involved in the digestion and utilization of food (salivary glands, intestine, fat body, Malpighian tubules). These organs are simultaneously involved in the intake, digestion and utilization of food. Finally, the relatively small, elementary or basal metabolic rate of the nervous system and musculature is completely independent of all hormonal activities (Sláma, 1975). Females that lack all sources of hormones (NSC-extirpated, 


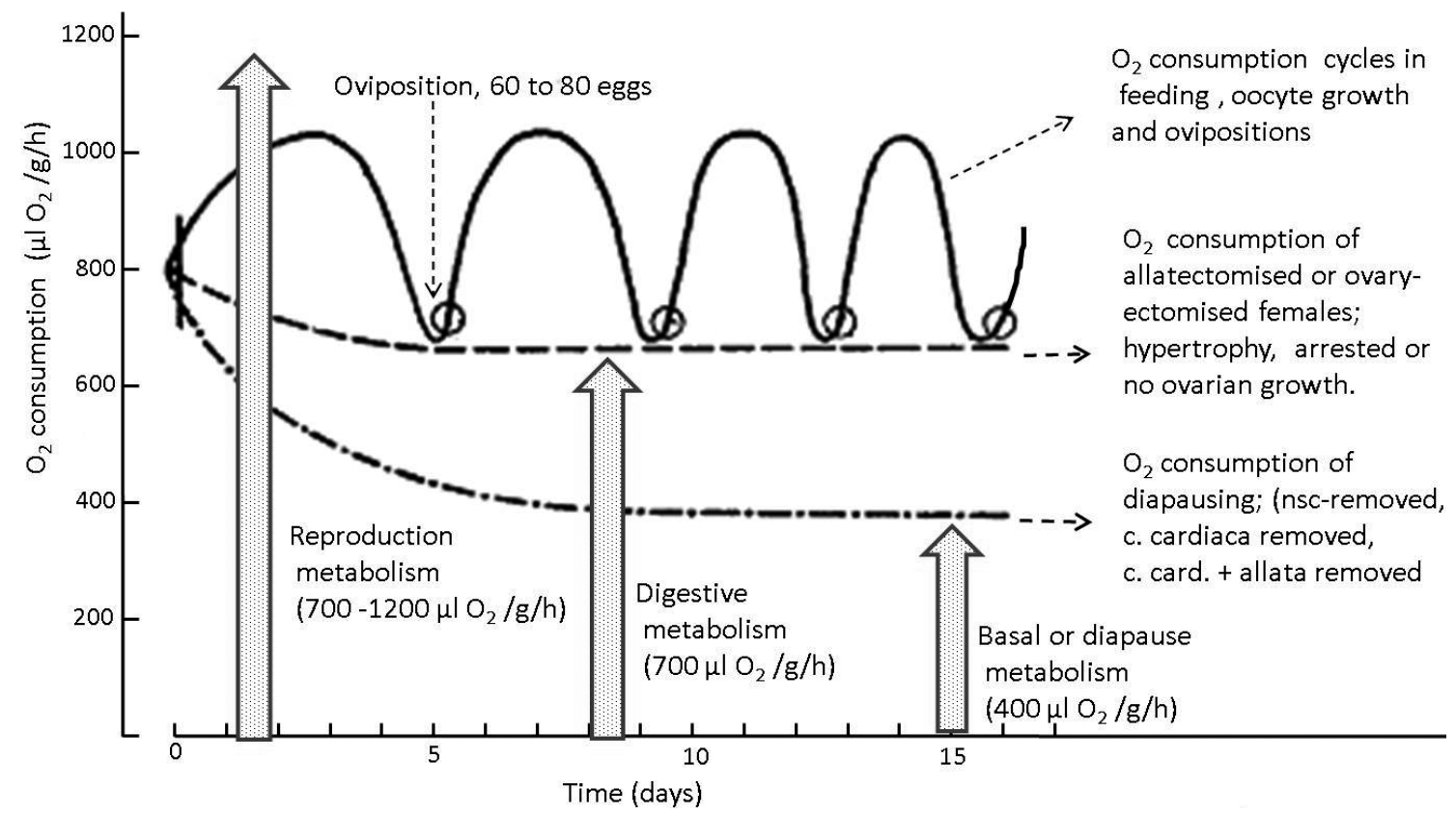

Fig. 5. The effects of removing the neurosecretory cells in the brain (NSC), corpora cardiaca (CC) and corpora allata (CA) on ovarian growth, feeding and respiratory metabolism during the reproductive cycles of adult females of Pyrrhocoris apterus (from Sláma, 1964b; adapted).

cardiac-allatectomised or diapausing females) that have a low, basal or diapause metabolism, necessary to sustain their survival, consume small amounts of water or food. The functions of the nervous system and musculature are not integrated by hormones but by a physiological feedback mechanism associated with an increase in locomotory activity (Sláma, 1965).

The selective advantage of the differential action of hormones on genetically determined target tissues and organs depends on the enormous potency of the central neuroendocrine system to control a complex of mutually interrelated metabolic functions. This enables, for example, the digestive functions controlled by $\mathrm{AH}$ to proceed normally even in the complete absence of JH (allatectomised females). On the other hand, ovarian growth controlled by $\mathrm{JH}$, cannot proceed normally without the nutritional functions controlled by AH. Under experimental conditions, however, treatment with juvenoids stimulate the ripening of a few eggs also in hungry, diapausing or starved females (Sláma et al., 1974). This is possible because they are able to draw on resources in their depleted fat body (see details for Rhodnius in Wigglesworth, 1970). The metabolic studies on Pyrrhocoris females also reveal that a single insect organ can serve as a target of more than just one hormone. This is illustrated by the telotrophic ovary of Pyrrhocoris, where the formation of primordial oocytes in the germarium proceeds by mitotic divisions stimulated by $\mathrm{AH}$. The ovarian follicle cells in the vitellarium grow and perform a single amitotic division in response to JH (Sláma et al., 1974).

These facts (Fig. 5) provide evidence that the epigenetic function of centrally produced hormones $(\mathrm{AH}, \mathrm{JH})$ is to determine the differentiation of target cells, the course of which depends on the nature of the inherited genetic in- structions coded on the genomes of these cells (Sláma, 1985). It has long been known (Hodková, 1976) that the most important environmental factors stimulating the release of hormones in adult Pyrrhocoris females are long days and warm conditions. This is perhaps the best example of the epigenetic function of hormones over peripheral genes (Sláma, 2013). In this context a question arises: what are the physiological and genetical factors responsible for the selective susceptibility of individual target cells to hormones. Not aware of the results shown in Fig. 5 and other endocrinological literature (review by Engelman, 1970), Smýkal and his co-workers recently stated that certain enzymes and genes in peripheral tissues and organs regulate the functions of centrally produced hormones. According to Smýkal et al. (2014b), RNA interference (RNAi) along with Met and Tai genes block ovarian development and suppress vitellogenin gene expression in the fat body of Pyrhocoris females reared under reproduction inducing environmental conditions. The loss of Met and Tai match the effects of CA ablation or natural absence of $\mathrm{JH}$ during diapause. These interpretations based on a poor knowledge of the relevant endocrinological literature could be a major discovery or complete nonsense.

Based on recent developments in molecular biology, the selectivity of insect target tissues to hormones could be related to the presence or absence of specific hormonal receptors (Gilbert, 2012; Riddiford, 2012; Jindra et al., 2013; Yamanaka et al., 2013; Jindra, 2014). The direct experimental evidence for this interpretation is still lacking (see the above mentioned Met and N5 adultoid of Jindra et al., 2013). The specificity of target tissues to hormones may also depend on changes in the response of certain genes during insect ontogeny. In other words, the response of genes to a hormone changes with the successive diversifi- 


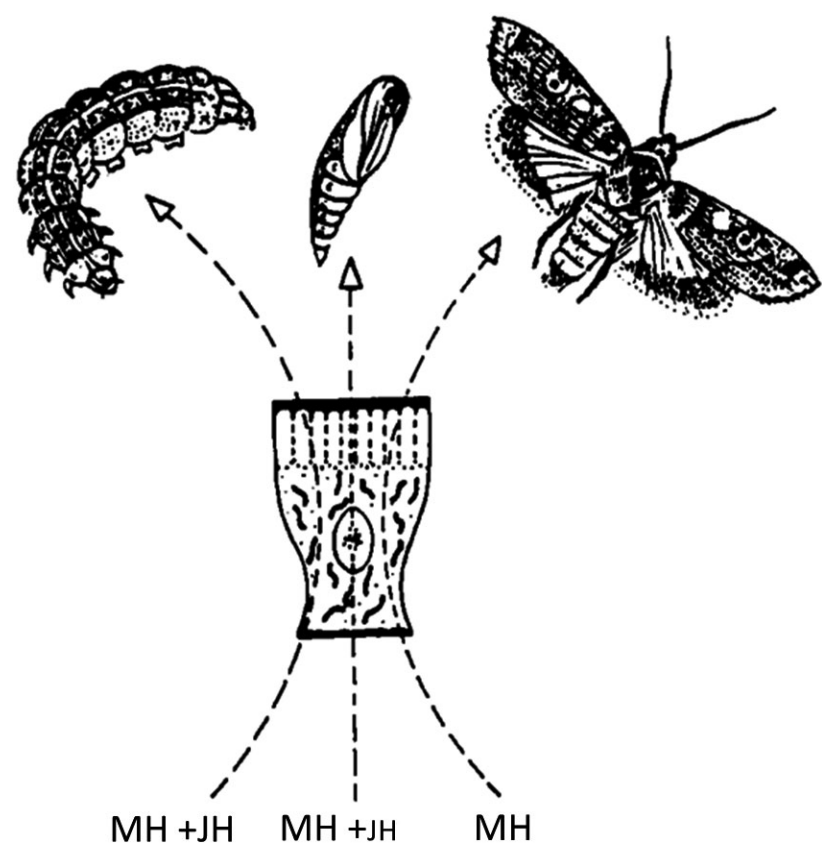

Fig. 6. Schematic outline of the hormonal theory of Piepho (1951) after Wigglesworth (1954, 1962, 1970). A single epidermal cell has three developmental options, larval, pupal and adult depending on whether there are high, medium or low concentrations of $\mathrm{JH}$ in the haemolymph.

cation of immature tissues and cells during development. The genes present on chromosomes in the larval epidermal cells, for example, which are sensitive to both $\mathrm{AH}$ and $\mathrm{JH}$ in the larval stage (see Figs 2 and 3) do not respond to these hormones in the adult. The problem remains, however, how could the epigenetic function of JH cope with 4000 JH-mimetic bioanalogues (Sláma, 1999).

\section{Endocrinology of exopterygote and endopterygote insects}

The larvae of hemipteran insects, for example, $R$. prolixus used in most of the hormonal studies of Wigglesworth (1954, 1962, 1970), undergo a substantial part of their morphogenetic development during embryogenesis. They hatch from eggs at an advanced, oligopod stage with three pairs of legs and externally everted wing lobes (Exopterygota; Novák, 1966). The process of larval-adult transformation in this case is relatively simple and occurs in the last larval instar, and mainly involves the differentiation of gonads, external genitalia and adult wings (see Figs 2 and 3). At the beginning of JH research, before WW-II, Wigglesworth reasonably concluded that each larval epidermal cell contained two latent developmental systems. The larval system, sustained and maintained by $\mathrm{JH}$ and a latent adult system, responsible for metamorphosis in the absence of JH (Wigglesworth, 1940). Currently, after 75 years, the original concept of two latent developmental systems of Wigglesworth (1940), could be considered as the best model of insect hormone action. Unfortunately, his original principle of two inherited developmental programmes, which he later abandoned (Wigglesworth, 1954, 1970), survived the confusing era of high, medium and low concentrations of JH (Piepho, 1951; Wigglesworth, 1954; Schneiderman \& Gilbert, 1964; Gilbert, 2012; Riddiford, 2012) in the form of Novák's $(1959,1966,1975)$ gradientfactor theory (review by Sláma, 2013).

During the 1950s, Wigglesworth visited Hans Piepho, an outstandidng insect endocrinologist in Göttingen, Germany. Piepho was widely known from his comprehensive work on the hormonal control of metamorphosis in the greater wax moth, Galleria mellonella (Piepho, 1943). The development of Galleria differs from that of Rhodnius mainly in the presence of a pupal stage during which the wing imaginal discs are evaginated (Novák \& Sláma, 1960). Piepho transplanted small pieces of pupal epidermis into the larvae of Galleria, which regenerated into cystlike vesicles whose epidermal cells moulted in synchrony with their hosts. Based on a careful analysis of the cytological structures of the implants, Piepho (1951) concluded that the epidermal cells of Galleria, as he states, "play ball" with the different concentrations of $\mathrm{JH}$. He thought that the pupal cells, after being implanted into a JH-rich larval medium, secreted a larval cuticle again. (Today we know he confused the unpigmented pupal cells of the vesicles for larval cells, which are incidentally of the same size; see Sláma \& Weyda, 1997). According to Piepho (1951), a high concentration of JH produces larval epidermal structures, medium concentrations pupal structures and zero or low concentrations an adult epidermis with a characteristic adult cuticle. It was assumed at that time that an epidermal cell of any insect stage had not only two, but actually three developmental options; larval, pupal or adult option determined, respectively, by a high, medium or low concentraion of $\mathrm{JH}$.

The straight-forward, concentration-dependent JH scheme of Piepho (1951) confused Wigglesworth (1954), who had no experience of working with the pupal stage. Therefore, he adopted the "high, medium, low" JH concentration theory of Piepho, and proposed a graphical scheme for the effects of JH on metamorphosis (Wigglesworth, 1954, 1970), which is shown in Fig. 6. Later on, the Wigglesworth scheme was upgraded by incorporating the moulting hormone theory of Williams $(1947,1952)$, see Fig. 7 (Schneiderman \& Gilbert, 1964). It became the dominant theoretical scheme of insect hormone action cited in textbooks of insect physiology (Nijhout, 1994; Nation, 2002; Klowden, 2007; Gilbert, 2012) and numerous review articles (Riddiford, 1985, 1996, 2008, 2012; Gilbert, 2009, 2012; Jindra et al., 2013).

There have been attempts to modernize Wigglesworth (1954) and Schneiderman \& Gilbert (1964) models of 3 developmental options for each epidermal cell. For instance, Williams \& Kafatos (1971) propose the existence of 3 master genes (larval, pupal and adult) operated by repressors activated specifically by high, medium and low concentrations of JH. They did not take into account that the expected reconstitution of larval characters from pupal (endopterygotes) or adult (exopterygotes) structures are unrealistic. Actually, the outlived larval structures and larval morphogenetic instructions on the chromosomes are 


\section{Old Model of Insect Hormone Action (after Schneiderman and Gilbert, 1964)}

1.

\section{Developmental cycles are stimulated by a moulting} hormone released from the prothoracic glands in response to hormone released from the brain. (Williams, 1948,1952; unfounded by Williams, 1987)

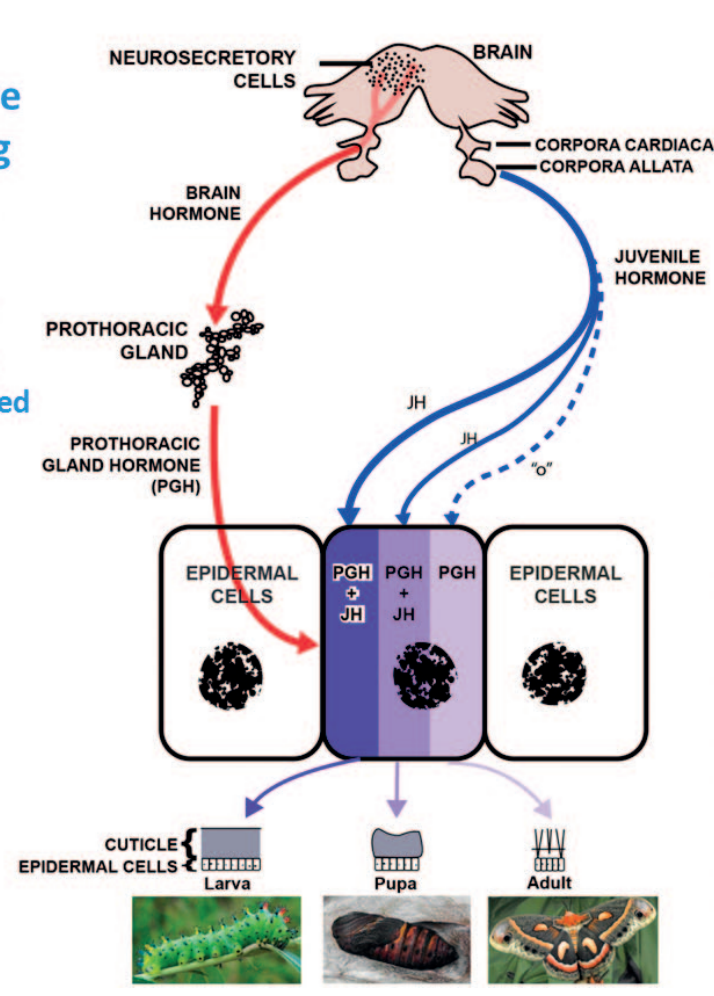

2.

Larval, pupal or adult epidermal structures are determined by the large, medium or zero concentrations of juvenile hormone. (Piepho, 1951; Wigglesworth, 1954; Schneiderman and Gilbert, 1961, 1964; Riddiford, 2011; Jindra et al., 2013)

3. Corpora allata produce the sesquiterpenoid $\mathrm{JH}-\mathrm{I}$, isolated from abdomens of the male Cecropia silkworms

(Jindra et al., 2013; Devillers, 2013)

Fig. 7. The widely accepted model of insect hormone action after Schneiderman \& Gilbert (1964), modified by Sláma (2013). Development is stimulated by a moulting hormone released from PG in response to PTTH from the brain and the formation of larval, pupal or adult epidermal structures is determined, respectively, by high, medium or low concentrations of $\mathrm{H}$.

disposed off during ontogeny (the Dollo's principle of irreversibility of evolutionary changes). For example, the hind wing rudiment in P. apterus, shown in Figs 1 and 3. Obviously, the stem cells of larval wings are destroyed during metamorphosis, so that it is impossible to regenerate a larval wing lobe, without millions of years of new evolutionary adaptations. Another example of the irreversibility of morphogenetic changes are the large, polyploid larval cells in Drosophila. These exclusively larval cells are formed after embryogenesis and enable larvae to grow rapidly. In contrast to the large polyploid larval cells, the pupal cells of Drosopila are relatively small, newly formed diploid cells, originating during the proliferation of the imaginal discs or histoblasts in the prepupal period. In this and other groups of Diptera, the pupal characters are produced by completely new cells, which are not the descendants of the polyploid larval cells. It is thus illusive to think that the small, diploid pupal cells could reconstitute under high concentrations of $\mathrm{JH}$, the giant polyploid larval cells. The larval-puparium intermediates are never induced in cyclorrhaphous Diptera by treatments with JH alone, although they are induced by injections of ecdysteroids (Žd'árek \& Sláma, 1972).

The main biological argument against the validity of the old hormonal theories of Piepho (1951) and Schneiderman \& Gilbert (1964) is that they violate the general biogenetic law of Heckel, about the repetition of phylogenetic stages in the course of animal ontogeny. Insects, like other animals, have distinct phylogenetic stages (Berlese, 1913; quoted by Novák, 1966; Sláma, 2013). According to these ontogenetic principles, a larval epidermal cell and its progeny, which metamorphose in the absence of $\mathrm{JH}$, achieve a higher, pupal or adult ontogenetic stage. It is impossible, therefore, for epidermal cells of these advanced morphogenetic structures to develop larval characters when exposed to high concentrations of $\mathrm{JH}$.

During the morphogenetic flux, the outlived developmental programmes become replaced or upgraded by fresh morphogenetic instructions of the new developmental stage. These facts rule out the possibility of the existence of "reversal of metamorphosis" (Sehnal, 1984), which is the main theoretical attribute of Piepho's theory. Currently, adherents of the hormonal theory outlined in Fig. 7, refrain from speaking about reversal of metamorphosis, which was experimentally refuted in 1975 by Sláma (1975, 1976). The relevant anatomical, morphological and physiological differences between exopterygote and endopterygote insects are discussed in a number of morphological publications (review by Pflugfelder, 1958; Novák, 1966, 1975). Ignoring these common morphological and physiological criteria, however, the well discussed differences between exopterygote and endopterygote insects, were recently analyzed with respect to different expression of the putative, Met and Kr-h1 genes, serving as JH-dependent repressors of deleterious precocious metamorphic changes (Konopová et al., 2011). Introducing tentative "precocious 
metamorphic changes" dependent on subordinated peripheral genes, like Met and Kr-h1, brings yet again further confusion and greatly complicates studies on insect hormones. A major problem of Met is the insufficient or ambivalent description of the methoprene antagonistic property of Met by Wilson \& Fabian (1986), which is automatically used as the main axiom of molecular biology (Gilbert, 2012; Riddiford, 2012; Jindra et al., 2013; Smýkal et al., 2014). The correct determination of the $\mathrm{JH}$-synergistic or JH-antagonistic properties of methoprene and other juvenoids has proved extremely difficult (Sláma et al., 1974) and a great technical challenge. The methoprene tolerant mutants of Wilson \& Fabian (1986) are taken for granted, without any supporting physiological evidence.

\section{The hormonal theory of Novák-Sláma}

The hormonal theories based on Schneiderman \& Gilbert (1964) model of high, medium or zero JH concentrations (see Fig. 7), are not generally accepted by all insect physiologists (see Bodenstein, 1953; Karlson, 1956; Novák, 1966, 1975, 1991; Sláma, 1985, 1999). Recently, Sláma (2013) distinguished two principal, alternative hormonal concepts in insects. The first is the widely used theory of Gilbert-Riddiford and the second the less well known theory of Novák-Sláma. Each of these theories is based on very different physiological grounds. The Gilbert-Riddiford theory is based on the following theoretical grounds: 1. Insect development is controlled by a moulting hormone released from $\mathrm{PG}$ in respone to a special, prothoracicotropic hormone (PTTH) of the brain; 2. The moult cycles and ecdyses are stimulated by ecdysone or endogenous Ecd released from the $\mathrm{PG} ; 3$. The $\mathrm{JH}$ in insects is the sesquiterpenoid, homofarnesoate ester, JH-I, secreted from the CA; 4. High concentrations of JH-I cause the development of larval structures, medium concentrations pupal structures and zero concentrations the formation of the adult structures (Fig. 7); 5. The presence of medium concentrations of JH-I in the last larval instar is necessary for inhibition of precocious proliferation of the imaginal discs; 6 . The action of centrally produced hormones depends on the activity of enzymes (JH-esterase) or genes (Met, Kr-h1), which are present in the peripheral target cells of the hormones.

The alternative, Novák-Sláma hormonal theory proposes that: 1. PTTH does not exist; 2 . PG is an exclusive target of JH, not PTTH, and its physiological functions do not depend on the induction of insect moults; 3. Ecdysone and Ecd are not insect hormones, they are released from many disintegrating larval cells (including PG), which results in the homeostatic synchronisation of moults and ecdyses; 4. The high, medium or low concentrations of $\mathrm{JH}$ are unimportant, as long as there is at least a minimum concentration of physiologically effective JH; 5. JH must not be present in the body of the last larval instar for metamorphosis to be initiated; 6 . The proliferation of imaginal discs is under the exclusive control of $\mathrm{AH}$ from the brain; ecdysone or Ecd without $\mathrm{AH}$ do not stimulate proliferation of imaginal discs; 7. The sesquiterpenoid JH-I is not a true insect hormone; it is a trivial excretory product of the male exocrine colleterial gland; 8 . The progress of larval growth and metamorphosis is integrated by two mutually dependent hormones ( $\mathrm{AH}$ and $\mathrm{JH})$; 9. The action of the centrally produced insect hormones is epigenetic, superimposed over the peripheral genes (Met, Kr-h1) or enzymes (esterase); 10. Insects whose development does not require feed-back responses or interference from the environment, undergo a genetically programmed, autonomic (hormone independent) metamorphosis (review by Sláma, 2013).

The experiments of Piepho (1951) in which he used epidermal implants in Galleria larvae have never been repeated or verified. In 1975, a reinvestigation of Piepho results using a newly invented experimental technique, based on artificially induced heterochronic development revealed that larvae or pupae with artificially induced patches of heterochronic epidermal cells (larval epidermal patches on the surface of a pupa or, conversely, pupal patches on that of a larva) developed in synchrony with the body of the host and moulted simultaneously into the next instar. According to the hormonal theories of Piepho and Gilbert-Riddiford, all specimens with heterochronic epidermal patches ought to develop into homochronic specimens, corresponding, respectively, to those that result from a high (larval), medium (pupal) or zero (adult) concentration of JH in the circulating haemolymph.

The results of the heterochronic experiments using Galleria (larval epidermal patches on pupae versus pupal epidermal patches on larvae), revealed no homochronization of the heterochronic epidermis (Sláma, 1975, 2013). There were only two types of hormonal effect: (i) In the presence of a minimum effective concentration of $\mathrm{JH}$, the larval epidermal patches on the pupal body developed into larval patches on the body of a heterochronic, supernumerary pupal host, i.e. the status quo effect of Williams; (ii) In the absence of $\mathrm{JH}$, the larval epidermal patches on pupae developed progressively into pupal patches on the adult body. The heterochronic epidermal status was again preserved. These results demonstrate that 40 years ago, insect epidermal cells of different ontogenetic stages (larval or pupal) followed their own, inherited morphogenetic programmes independently, irrespective of the presence or absence of $\mathrm{JH}$ in the haemolymph. The reversal of development, from adult to larval (exopterygotes), or pupal to larval structures (endopterygotes) did not occur, in spite of high doses of $\mathrm{JH}$ analogues (5000-fold in excess of ED-50).

The results of the above experiments (Sláma, 1975), provide clear experimental evidence that the most important factor determining the response of a cell to insect hormones is the previously attained morphogenetic stage. This decisive endocrinological condition was first fully comprehended by Novák $(1959,1966)$ in his GF theory of insect hormone action. This theory stems from Wigglesworth's (1940) concept of two latent developmental systems in each epidermal cell. According to Novák (1959, 1966, 1967), certain epidermal cells contain a hypothetical GF, which enables them to survive and metamorphose further into adult structures in the absence of JH. Other tissues and cells, specifically larval cells containing no GF, are programmed to die after termination of the larval stage. 


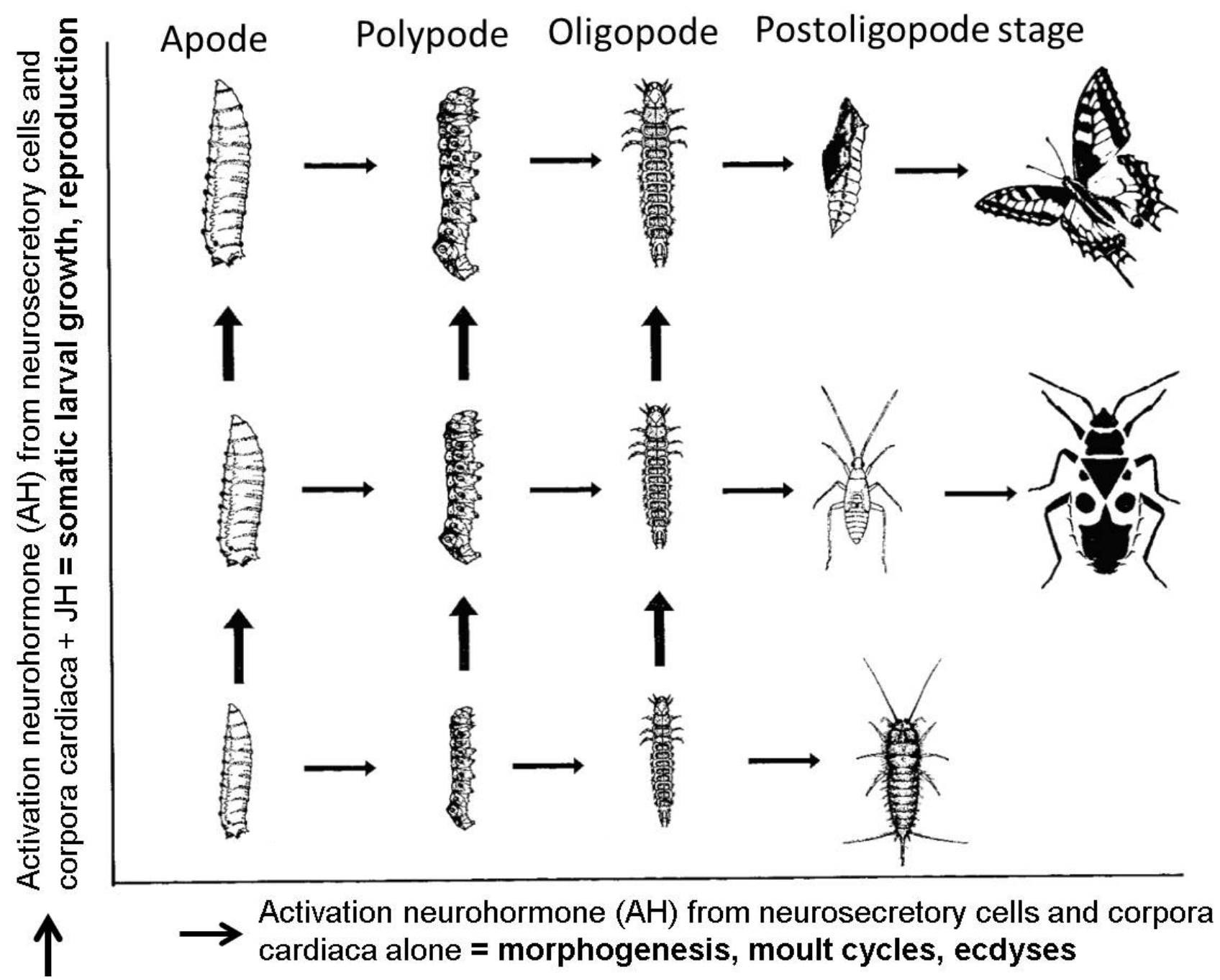

Fig. 8. Alternative model of the hormonal control of insect metamorphosis, which depends on the simple interaction of two hormones secreted from the central neuroendocrine system $(\mathrm{AH}+\mathrm{JH})$ (adapted from Sláma, 1975, 1995, 2013).

This difference between larval and adult stem cells is the main biological principle of insect metamorphosis. Novák (1959) proposed his GF theory long before the role of genes were elucidated. Later on, in 1975 and 1991, Novák emphasized that the hypothetical GF could be a part of the DNA molecule, i.e. the genes. Currently, after more than 55 years, GF may look like a naive substitution for the functions of genes. Unfortunately, the GF theory of Novák and the results of the heterochronic experiments by Sláma (1975), were overshadowed by the widely accepted hormonal theory of Schneiderman \& Gilbert (1964), shown in Fig. 7. I am convinced, however, that these alternative theories of insect hormone action will open the eyes of a new generation of molecular biologists and stimulate them to try to elucidate the interactions between hormones and regulatory genes.

The search for new analogues of insect JH between the years 1975 and 1980, discovered hudreds of new synthetic analogues of $\mathrm{JH}$, isoprenoid and nonisoprenoid, including peptidic juvenoids (Poduška et al., 1973), which are among the first $\mathrm{JH}$ analogues to be discovered with a biological activity of more than 100,000-fold that of JH-I (Sláma et al., 1974; reviews by Sláma, 1985, 1999, 2013). In spite of the great variation in $\mathrm{JH}$ activity of the 4000 juvenoids (8 orders of magnitude range), the most potent and the least effective JH mimics, all perfectly duplicated the effects of an implanted CA (Sláma, 1999). This is anthropomorphically similar to somebody turning an electrical switch on and off. The presence of $\mathrm{JH}$ turns the imaginary switch to a $(+\mathrm{JH})$ or the "status quo" position, while the absence of $\mathrm{JH}(-\mathrm{JH})$ would inadvertently divert the developmental programme towards the next morphogenetic stage (metamorphosis). Obviously, a high, medium or low pressure applied to the switch by a human operator is unimportant. The most important in this respect is the nature of electrical appliance, a lamp or radio, connected to the electrical circuit (i.e the morphogenetic developmental instructions incorporated into the genome during the millions of years of insect evolution; Sláma, 1985).

A schematic outline of the hormonal theory of NovákSláma (for a review see Sláma, 2013) is presented in Fig. 8 . It shows regulation of insect development and metamorphosis by a simple combination of two centrally produced hormones. The $\mathrm{AH}$ from the NSC in the brain is a hor- 


\section{Category of neurosecretory structures}

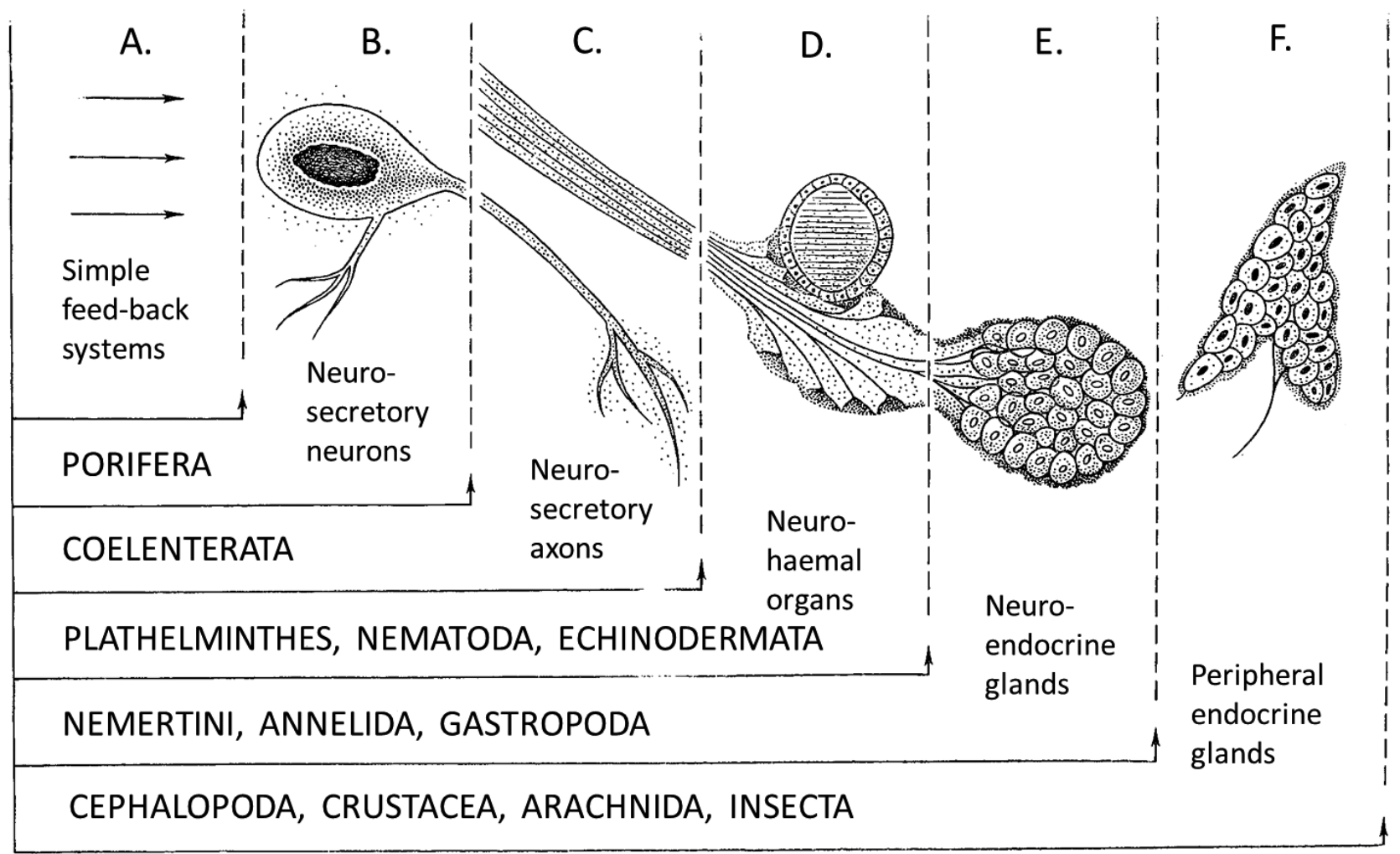

Fig. 9. Evolution of neuroendorcine systems during the phylogenesis of invertebrate animals (from Sláma, 1982).

monal messenger that translates suitable environmental conditions for initiation of moult cycles and ecdyses into chemical message. The associated $\mathrm{JH}(\mathrm{CAH})$, cooperates in stimulating somatic growth in larvae and reproduction in adults (Fig. 8). It is important that the inherited developmental instructions coded on the genome are more important for the resulting development than the hormones (the hormone independent development, see below). The main reason why the system needs the hormones secreted by the central neuroendocrine system is that the genes on the chromosomes in the peripheral cells do not see, hear, or sense changes in environmental conditions. This is why the centrally produced hormones $(\mathrm{AH}, \mathrm{JH})$ that evolved over millions of years superimpose an epigenetic control over the genes in the peripheral cells. In other words, the hormones tell the genes when it is time to start realizing their inherited developmental roles (Sláma, 2013).

In contrast to all previous hormonal theories (Piepho, 1951; Schneiderman \& Gilbert, 1964; Novák, 1966; Wigglesworth, 1970; Gilbert, 2012) the hormonal theory of Novák-Sláma depicted in Fig. 8 does not include PTTH and a moulting hormone. The existence of a moulting hormone was proposed very early by Wigglesworth (1940). Later it was supported by Williams $(1947,1952)$. The growing experimental evidence that certain insects can moult several times in the complete absence of PG (Delbecque \& Sláma, 1980; Sláma, 1980a, 1983), resulted in the moulting homone being more or less limited to ecdysone. Williams (1987) abandoned his original, brain-PG theory when he recorded a large release of extra-PG Ecd from the pupal intestine of Manduca sexta. This disappointed adherents of the widely publicized, PTTH-PG concept of GilbertRiddiford (Gilbert, 2009, 2012; Riddiford, 2012, Jindra et al., 2013). Recently, the mysterious physiological function of insect PG was elucidated by Sláma \& Lukáš (2013) who showed that the PG in insects is a subordinated target of $\mathrm{JH}$ (not PTTH). It is functional only in actively feeding young larvae (not in the last larval instar) when it releases an adipokinetic superhormone, which enables insects to feed on dry food and survive by generating metabolic water from the combustion of dietary lipids.

\section{Comparative physiology of invertebrate endocrine systems}

Novák (1966) used the phylogenetic analysis of insect development of Berlese (1913) to study the hormonal relationships in different groups of insects. In his GF theory, Novák (1959) predicts that the big morphological differences between different larval forms (apode, protopode, polypode, oligopode stages of Berlese) are determined when $\mathrm{JH}$ is first secreted in the course of embryonic development. These predictions were later confirmed by the discovery of JH effects ("paper factor") and effects of other JH analogues on embryogenesis in P. apterus (Sláma \& Williams, 1966b; Riddiford, 1970). The GF theory of Novák $(1959,1966)$ and the famous evolutionary conclusions of Berlese were unreasonably criticised by Sehnal et al. (1996). In addition to Novák (1966), other books on invertebrate hormones (Gersch, 1964; Highnam \& Hill, 1969; Tombes, 1970) also indicate the existence of distinct 

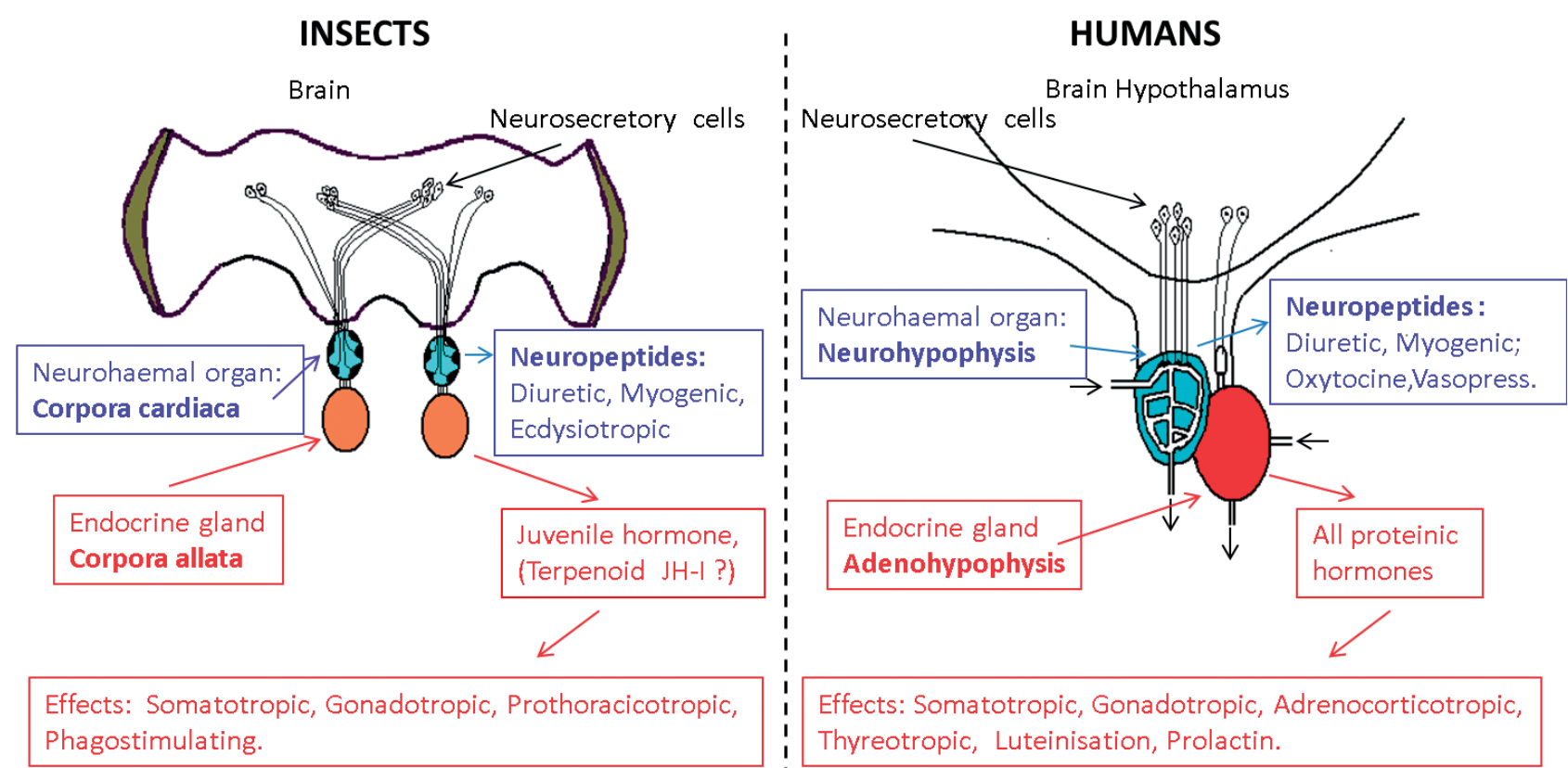

Fig. 10. Evolutionary links between the neuroendocrine systems of insects and humans. The homologous endocrine structures are neurosecretory cells (NSC) in insect brains and the NSC in the mammalian hypothalamus; neurohaemal organs c. cardiaca in insects and neurohypophysis, and endorine glands c. allata of insects and adenohypophysis in mammals (compiled from Scharrer \& Scharrer, 1937, 1944; Hanström, 1939, 1953; and Novák, 1975).

evolutionary similarities between the neuroendocrine systems of different invertebrates.

Fig. 9 shows the evolution of the neuroendocrine systems in different phylogenetic groups of invertebrate animals (Sláma, 1982). Evidently, the origin of the neurosecretory systems can be traced back to the coelenterates. The primitive secretory neurons show modifications at the terminals of axons in planarians and flat worms, followed by neuroendocrine glands in annelids and peripheral endocrine glands in cephalopods, crustaceans (sinus gland) and insects (PG). The primitive physiological predecessors of insect $\mathrm{JH}$ are manifested in lower invertebrates by the general tendency of the endocrine system to support somatic growth and temporarily suspend reproduction. For example, the secretory nerve cells located around the prostomium of Hydra produce a chemical compound, probably a peptidic hormone, which inhibits reproduction of the polyp. The removal of these nerve cells from the prostomium causes premature reproduction associated with the formation of new individuals. Similar JH-like neuroendocrines, favouring somatic growth and inhibiting reproduction, occur among the neurohormones secreted by the cephalic ganglia of planarians, nemerteans, flat worms and, especially, annelids (Sláma, 1982). The selective developmental advantage of all these, JH-like neurohormonal systems in invertebrates, is that they stimulate somatic growth in the early developmental stages that accumulate the reserves necessary for the future production of eggs.

\section{Evolution of the insect and human neuroendocrine systems}

Insects are considered to be a phylogenetically distant group of animals in relation to mammals. Due to this, scientists mostly refrain from investigating possible hormonal analogies in these two groups. Recent progress in molecular biology and genetics, however, indicate that as much as $37 \%$ of genes found in Drosophila have counterparts in the human genome (Devillers, 2013a, b). Moreover, certain systems like insect and human hearts are built on exactly the same, involuntary, purely myogenic principles. In addition, the primordial origins of insect and human hearts are orchestrated by identical sets of genes (review by Sláma, 2012). It is quite feasible, therefore, that in spite of the relatively large phylogenetic difference between the prostomia (invertebrates) and deuterostomia (vertebrates), certain elementary principles of neuroendocrine systems are conservatively preserved in spite of the millions of years of independent evolution.

A long time before Williams (1947), Piepho (1951), Novák (1959), Wigglesworth (1962) and Schneiderman \& Gilbert (1964) proposed their hormonal theories, the relationships between insect and human hormones were intensively studied by physicians. The textbook on invertebrate hormones by Hanström (1939), for instance, lists a great number of structural and functional analogies between the neuroendocrine systems of invertebrates and humans. These important facts remained concealed and overshadowed by predominating biochemical interests. The structural and functional similarities of the neuroendocrine systems of insects and humans are summarized in Fig. 10. The most important common denominator of all neuroendocrine systems in the animal kingdom are the neurosecretory cells in the brain (NSC). There are striking structural homologies between the NSC in the hypothalamus section of the human brain and the NSC located in the central or lateral parts of the insect brain. In addition, in insects there are also neurons with neurosecretory functions in the gan- 
glia of the ventral nerve cord (review by Raabe, 1982). Further homologous hormonal centers in insects and humans are the anatomical structure in the neurohaemal organs, which contain the terminals of neurosecretory axons (Fig. 10). Such organs are the neurohaemal structure in c. cardiaca (CC) of insects, which are homologous with the human neurohypophysis. The associated neuroendocrine glands, the c. allata (CA) in insects are for many physiological reasons homologous with the human adenohypophysis. These evolutionary relationships (Fig. 10), were constructed on basis of the very old, but still valid work of Scharrer \& Scharrer (1937, 1944), Hanström (1939, 1953) and Novák (1966, 1975).

The anatomical and morphological similarities between the neuroendocrine systems of insects and humans are well reflected in the corresponding chemical structures of particular hormones (Fig. 10). For example, the NSC of both insects and humans produce neuropeptides or proteins, which were known initially only as Gomori positive materials rich in -S-S- or - SH- groups (review by Highnam \& Hill, 1969; Raabe, 1982). The principal neurohaemal organ, the $\mathrm{CC}$ in insects releases a few neuropeptides (Nässel, 2002), which are structurally related to the oxytocine and vasopressine secreted by the human neurohypophysis. Moreover, the main physiological functions of these neuropeptides are also similar, being mainly myogenic and diuretic. The $\mathrm{JH}$ released from the c. allata in insects, which is unique due to a series of 4000 biological mimetic analogues (Sláma, 1999), has pronounced somatotropic (larval somatic growth), gonadotropic (ovarian growth) or prothoracicotropic (PG stimulation) effects, especially in the early developmental stages (reviews by Novák, 1966, 1975; Sláma et al., 1974; Sláma, 2013). These effects of insect c. allatum hormone correspond closely to similar, somatotropic, gonadotropic, adrenocorticotropic, thyreotropic and related hormonal effects of the human adenohypophysis, which produces only proteinic hormones (review by Hanc, 1959). If this is the case then it differs greatly from the evolutionary links presented in Fig. 10 as the hormone of the insect c. allatum is not thought to be a protein, which is contrary to the evolutionary schemes outlined in Fig. 10, but a low-molecular, sesquiterpenoid JH-I (Röller \& Dahm, 1970; Nijhout, 1994; Nation, 2002; Klowden, 2007; Gilbert, 2012; Devillers, 2013a, b; Jindra et al., 2013). It is unlikely that there has been evolutionary substitution of a proteinic hormone for an isoprenoid. Actually, some endocrinologists (Novák, 1966, 1975; Sláma et al., 1974; Sláma, 1999) argued a long time ago that the true CA hormone of insects should also be a protein, not an isoprenoid (review by Sláma, 2013).

\section{The isoprenoid JH-I is not an insect hormone}

As pointed out above, the sesquiterpenoid nature of insect CA hormone is in conflict with evolutionary principles outlined in Fig. 10. However, this is based on the nature of the $4000 \mathrm{JH}$ mimetic analogues that were discovered by applying them only to the outside of the body (Sláma, 1999). This does not mean that these strongly lipophilic $\mathrm{JH}$ analogues would not be effective if injected or fed to

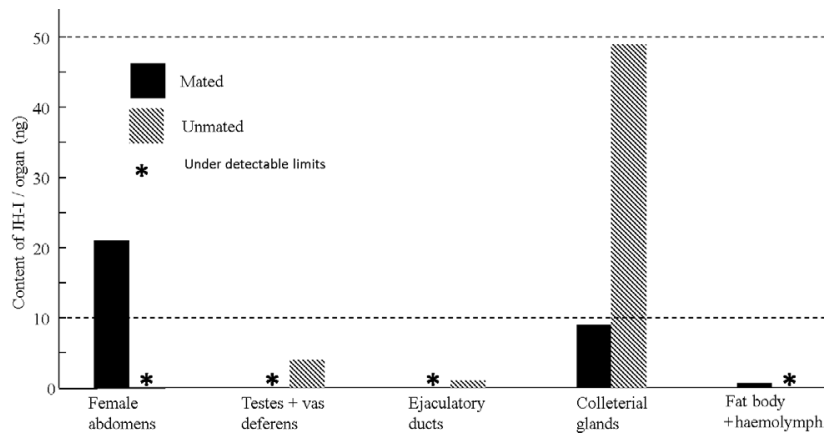

Fig. 11. Combined chromatography/mass spectrometry data showing the distribution of epoxy homofarnesoate (JH-I) in virgin and mated females, and in the reproductive organs of adult male Hyalophora cecropia (from Paroulek \& Sláma, 2014; with permission of Brill Publ.).

insects (Sláma, 1981). For practical reasons, however, the bioassays of JH were made topically, which excludes all of the nonlipophilic chemical compounds as they are unable to penetrate the lipidic, hydrocarbon or waxy epicuticular coating, which protects insect from water loss. Under physiological conditions, the endocrine gland (CA) releases its hormone into the polar, water soluble haemolymph. Nobody knows, whether the true CA hormone can also pass through the lipid coated cuticle from outside the body. The insect-plant interactions mediated by $\mathrm{JH}$ are always based on the dietary effects (review by Sláma, 1979), except for the JH-mediated effects of the serendipitous "paper factor" (Sláma \& Williams, 1966a).

After discovery of the "pseudojuvenile" or JH-mimetic effects more than 50 years ago (Sláma, 1961, 1962), doubts were expressed about the identity of the JH-active extracts from Cecropia and the hormone secreted by the CA (review by Sláma et al., 1974). Physiologists were puzzled by the inconsistency in the occurrence of JH-activity only in males and not in females. The insect JH-activity of the lipid extracts of microorganisms, plants, vertebrate organs and other biological sources raised further difficulties (review by Sláma, 1971). There were possible explanations based on synthesis of JH at first in the CA (Williams, 1963), followed by its accumulation in the male accessory sexual glands (Meyer et al., 1965; Shirk et al., 1976). This explanation was unreasonable, because animal hormones never accumulate in their target organs (Pflugfelder, 1958; Hanc, 1959). A more recent alternative explanation is that the sesquiterpenoid JH-I could be simultaneously biosynthetised both in the endocrine CA and in the purely exocrine, peripheral accessory sexual glands (De Loof et al., 2013, 2014). This may be true for some common metabolites, but not for hormones secreted by particular endocrine glands.

Because of the above mentioned problems over the identity of the CA hormone, the distribution of the sesquiterpenoid JH-I in adult Cecropia silkworms was reinvestigated using advanced methods of chromatography/mass spectrometry (Paroulek \& Sláma, 2014). The results of this study are presented in Fig. 11. They can be briefly summarized as follows: 1 . There was no JH-I in virgin females, 
however, females receive JH-I with male ejaculate during courtship; 2 . The JH-I in males is exclusively in the lumen of the exocrine, accessory sexual (colleterial) glands and in small amounts also in the interconnected, male reproductive organs (ejaculatory ducts, vas deferens, testes); and 3. In contrast to the simultaneous presence of the isoprenoid Vitamin E, JH-I is never present in measurable amounts in the male fat body and haemolymph. The conclusion, therefore, is that the terpenoid JH-I is the product of the exocrine colleterial glands of male Cecropia (Paroulek \& Sláma, 2014). These results confirm the 50-year-old prediction (Sláma, 1962; Novák, 1966, 1975; Sláma et al., 1974) that the lipid extracts of Cecropia silkworms do not contain the CA hormone. The true $\mathrm{CAH}$, when found, is likely to be a peptide or protein, based on the evolutionary schemes in Fig. 10. It is a great pity that the persistent belief in a isoprenoid JH-I (Devillers, 2013a, b) and its receptor (Jindra et al., 2013; Jindra, 2014; Smýkal et al., 2014a) hindered investigations into the real identity of the CA hormone for such a long time.

\section{The JH receptor}

The common pharmacokinetic theory explains the action of hormones by specific binding with intracellular or membrane receptor sites (review by Gilbert, 2012). According to Sláma et al. (1974, p. 264) and Sláma (1978), there are two types of hormonal binding with a tentative receptor: (a) The hormonal responses are elicited by a simple isosteric binding with the receptor; and (b) The responses that require specific biophysical interactions between the ligand and the receptor (Sláma, 1978). For the first type, any molecule that happens to fit into the receptor pocket is automatically hormonally active. Examples are the 4000 synthetic analogues of JH (Sláma, 1999). Examples of the second type are the mammalian estrogenic hormones. In this case the weakly active phytoestrogens occupy or block the receptor pocket and cause antiestrogenic activity, which prevents the action of the strong, natural estrogens such as estrone or estradiol (Sláma, 1980b). The synthetic $\mathrm{JH}$ analogues were earlier used to screen for possible antijuvenile activity of the antiestrogenic type, using 200 little active or inactive but structurally similar juvenoids, but not a single case of antijuvenile activity was recorded (Sláma et al., 1974). Thus, a given JH-active compound can either bind with the ligand and, therefore, exhibit JHactivity or not, without JH-antagonistic effects. Because of the strong, lipophilic properties of JH-analogues they have a tendency to stick nonspecifically to a trivial albuminoid and other proteins, which is the main reason for earlier failures to isolate the receptor of $\mathrm{JH}$. Recently, Jindra and his colleagues (Jindra et al., 2013; Jindra, 2014) succeeded in isolating the receptor of the fictive sesquiterpenoid $\mathrm{JH}$ hormone (JH-I). Presumably, this receptor can also bind with the 4000 isoprenoid or nonisoprenoid JH analogues.

The antihormonal, resp. antijuvenile, effects in insects were comprehensively reviewed for the first time by Sláma (1978). This revealed that the tentatively synergistic or antagonistic effects of insect hormones are extremely difficult to determine, because tentative antihormonal action can be

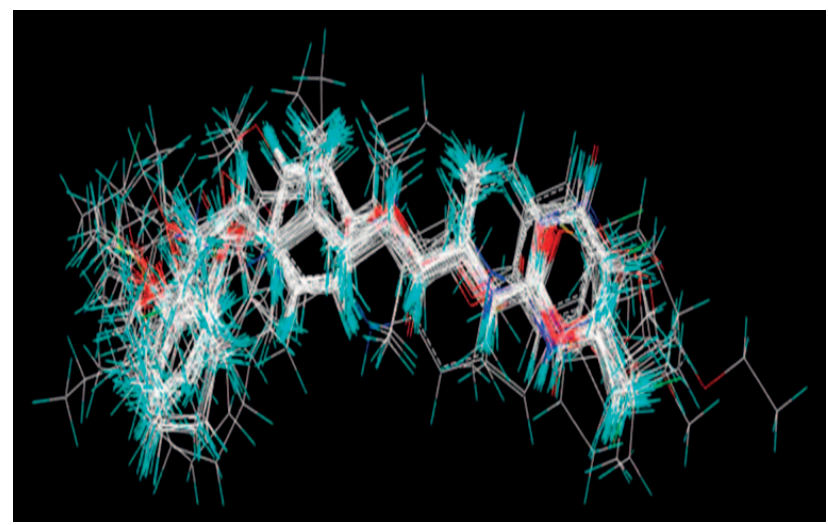

Fig. 12. The 3D QSAR analysis of structural-activity relationships based on determination of JH activity during the pupaladult transformation in Drosophila melanogaster. The structures indicate superpositional alignment of $86 \mathrm{JH}$-active bioanalogues (from Farkaš \& Polakovičová, 2013).

ascribed to various antifeedants, antimetabolites, protein denaturants and toxic compounds. This serious non-specificity may also apply to the "antijuvenile hormone" effects of ageratochromenes, known as precocenes, discovered by Bowers et al. (1976). Theoretically, the antijuvenile effect in insects should appear as a prothetely, manifested for instance by a premature inhibition of the secretory activity of the CA. This type of antijuvenile activity was described by Murakoshi and his co-workers (Murakoshi et al., 1975) in caterpillars of the commercial silkworm, Bombyx mori. The "antijuvenile" substances, such as kojic acid, diterpenic abietic acid and a number of other chemical compounds, produce precocious pupation after 3 moults instead of the usual 4 moults (for review see Sláma, 1978). Not being aware of these common "antijuvenile" materials, Yamanaka et al. (2013) and Smýkal et al. (2014a, b) assume that the premature, prothetelic moults in Bombyx are caused by the manipulation of Met and other peripheral genes.

From 1970 to 1990 , the structure-activity relationships of $\mathrm{JH}$ analogues were usually evaluated by the highest score of JH activity recorded in bioassays (for a review see Sláma, 1971, 1985, 1999; Henrick, 1982, 1995). The group of JH-active compounds was characterized by a more or less common molecular size, corresponding to 15 to 17 carbon atoms, slightly polar functional groups on both ends of the molecule and by their lipophilic physico-chemical properties (Sláma, 1971; Sláma et al., 1974; Henrick, 1982). Recently, the determination of the structure-activity relationships of JH-analogs was considerably improved by the computerized analysis known as COMFA and COMSIA, or 3D QSAR structure-activity relationships (Devillers, 2013c; Farkaš \& Polakovičová, 2013). Using the pupal-adult bioassay for determination of $\mathrm{JH}$ activity in Drosophila, Farkaš \& Polakovičová (2013) subjected 86 juvenoids to the computer mediated analysis in the hope of characterizing the receptor-protein pocket of JH. Fig. 12 shows a practical example of the results obtained by Farkaš \& Polakovičová (2013). It shows the superpositional alignment of 86 juvenoids tested in the pupal-adult bioassay for $\mathrm{JH}$ activity in Drosophila, which indicates the approximate 
shape of the receptor protein pocket for JH. Based on this 3D QSAR method, these authors devised several new candidate chemical structures for the potentially most effective juvenoids.

The most active JH-analogues investigated by Farkaš \& Polakovičová (2013) were effective at $\mathrm{ED}_{50}$ concentrations in the range of picomoles per pupa. The first reports of $\mathrm{JH}$ activity at picomolar ranges were those for the "peptidic" juvenoids in larvae of $P$. apterus (Poduška et al., 1973; Sláma et al., 1974). The high JH activity of the peptidic juvenoids, however, completely disappeared when the central L-alanin amino acid was replaced by unnatural D-alanin optical antipode. This shows that, in contrast to the more or less "flexible" isoprenoid juvenoids, a simple stereochemical change in the "rigid" peptide molecule can produce a million-fold change in JH activity.

There were several attempts to isolate the proteinic receptor of JH or specify the synergistic or antagonistic properties of the $\mathrm{JH}$ analogues (review by Sláma et al., 1974). This laborious kind of work was frustrated by the strong lipophilic character of JH-III, JH-I and methoprene, which bind nonspecifically to a number of the nontarget proteins (for references see Sláma, 1999). The methoprene tolerant, JH-antagonistic effects revealed using relatively simple synergistic-antagonistic methods (Wilson \& Fabian (1986) were widely publicized later in connexion with the Met gene (reviews by Riddiford, 2008, 2012; Jindra et al., 2013). Recently, the proteinic JH receptor of JH was identified by Jindra (2014) as bHLH-PAS protein Met, whose loss could tentatively cause precocious metamorphosis.

According to the recent COMFA and COMSIA analyses carried out by Farkaš \& Polakovičová (2013), there is most probably only one, widely open receptor pocket for all JHactive compounds, which was predicted a long time ago by Sláma et al. (1974, p. 264). This JH receptor most likely belongs to a family of classical nuclear receptors, possibly the Drosophila hormone receptors (DHRs). The 3D QSAR model of Farkaš \& Polakovičová (2013) does not support the view of Jindra (2014) that the Met protein is the target of JH binding. The indicated Met protein belongs to the family of basic and helix-loop-helix (bHLH) and PAS proteins, which show extensive nonspecific binding. The pharmacophore model proposed by the 3D QSAR analysis (Farkaš \& Polakovičová, 2013) excludes the possibility of JH binding with Met (Jindra, 2014).

\section{The autonomic (hormone independent) regulation of metamorphosis}

Previous hormonal studies involving the ligaturing of sawflies (Hymenoptera: Tenthredinoidea) revealed, surprisingly, that the most important insect hormones of the cephalic neuroendocrine system are not needed for regulating metamorphosis in this group (Sláma, 1964c). Indeed, in the complete absence of all cephalic endocrinal sources (brain, CC, CA), the headless pronymphal larvae developed into headless pupae, which metamorphosed into headless adults. The hormone indepenent metamorphosis of sawflies (Sláma, 1964c) conflicted with the then current hormonal theory based on the necessity of a moulting hor-

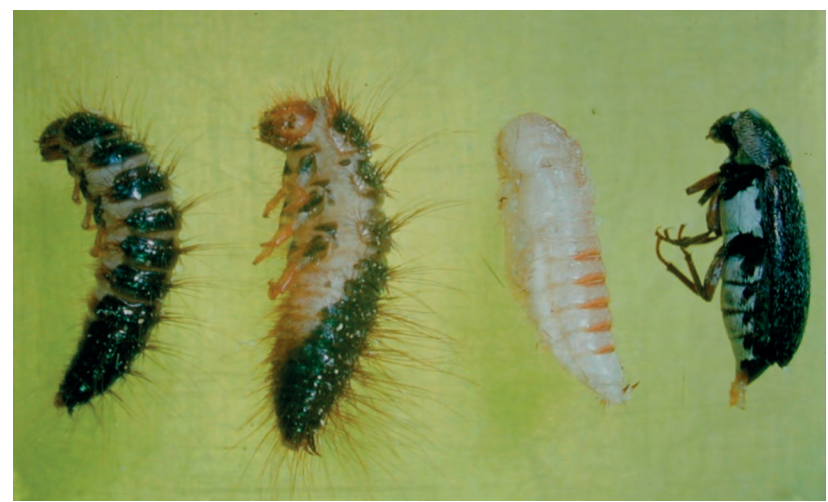

Fig. 13. Developmental stages of Dermestes vulpinus F., the stage-specific epidermal structures; the dark pigmented hairs and dark cuticle in the penultimate $\left(\mathrm{L}_{5}\right)$ and last $\left(\mathrm{L}_{6}\right)$ larval instars, the white, unpigmented pupal cuticle with brown epidermal tubercles and gin traps on the tergites, and the dark pigmented cuticle with grey hairs on the abdomen of the adult.

mone from PG (in Lepidoptera: Piepho, 1951; Williams, 1952; Gilbert \& Schneiderman, 1961; Schneiderman \& Gilbert, 1964; and Hemiptera: Wigglesworth, 1954; Novák, 1959).

Perhaps the first evidence of hormone independent metamorphosis in insects came from studies on isolated body fragments of the mealworm, Tenebrio molitor (Janda, 1933). The phenomenon was later rediscovered in the carpet beetle (Dermestes vulpinus; Sláma et al., 1974), the Colorado potato beetle (Leptinotarsa decemlineata; Hsiao et al., 1975) and again in T. molitor (Delbecque et al., 1978). In D. vulpinus, the larval, pupal and adult stages exhibit stage-specific epidermal structures, which in the case of larvae are long black hairs and black tergites, in pupae unpigmented white cuticle with special brown tubercles scattered over the tergites and in adults a dark cuticle with grey hairs (see Fig. 13). It is obvious that such fundamentally different, stage specific epidermal transformations require substantial integumental reconstructions. It is more important, however, that all these reconstructions take place in the absence of the so called metamorphosis hormones. The critical period of larval-pupal transformation, is here protected by physiological antijuvenile mechanism, which restrains possible effects resulting from incomplete cessation of CA activity. Exogenous juvenoid treatments of the last larval instar never result in extra-larval moults or intermediates, as is usual in many other insect groups, as these treatments are always followed by a prolonged developmental arrest. In other words, the last instar larvae of this species treated with JH never produces supernumerary larval moults or larval-pupal intermediates (Sláma et al., 1974). A similar type of prolonged suspension of metamorphosis after juvenoid treatments occurs in sawflies (Athalia), beetles (Dermestes, Tenebrio), flies (Drosophila, Sarcophaga) and bees (Aphis), see Sláma et al. (1974).

In $D$. vulpinus, metamorphosis set in motion by removal of all cephalic hormonal sources (note that the PG in $D$. vulpinus are locaed in the head capsule and can be isolated by ligaturing) is a hormonally independent process 

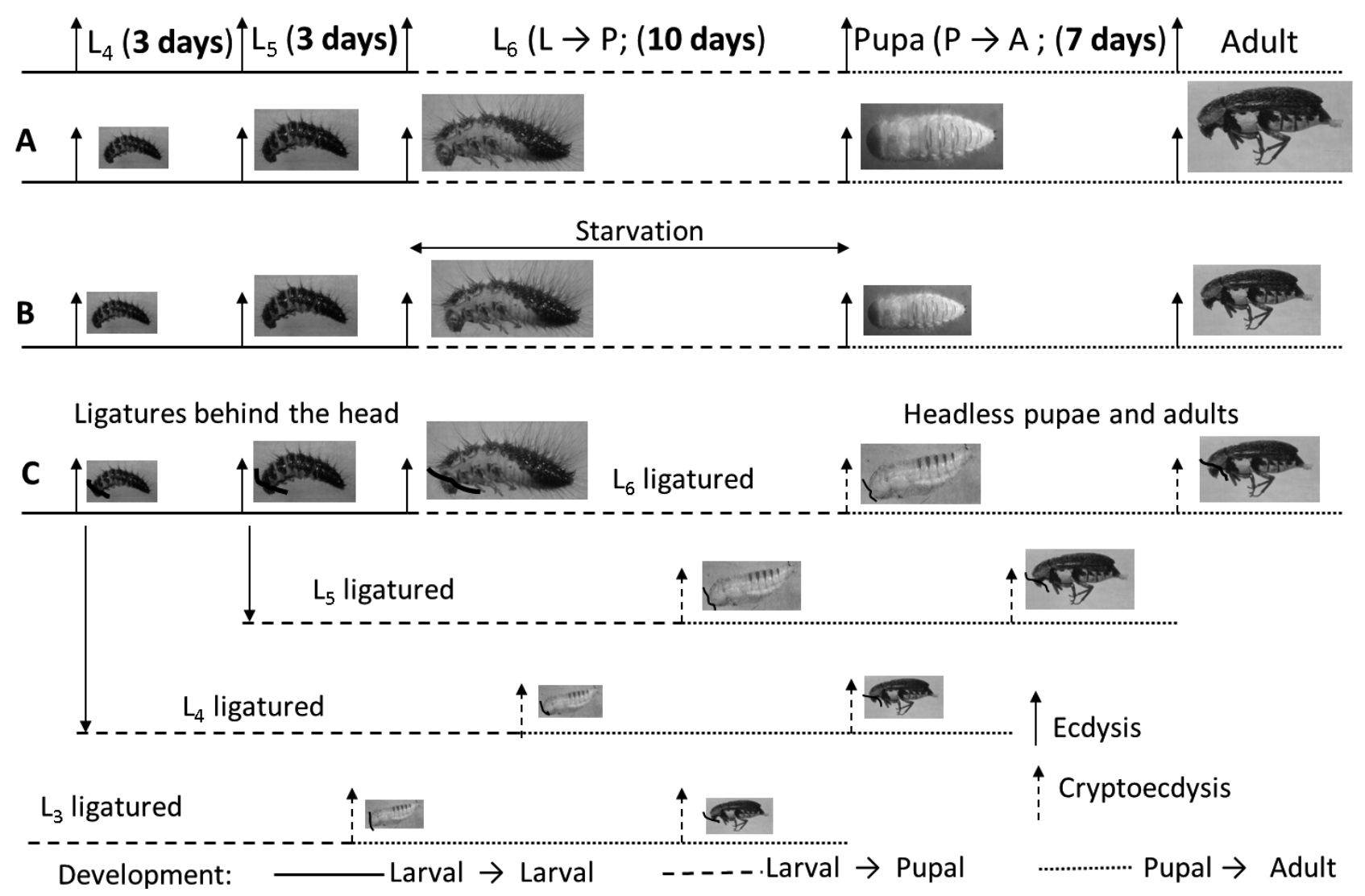

Fig. 14. Schematic outline of the autonomic (hormone independent) metamorphosis in Dermestes vulpinus. A - normal development showing the 3-day larva-larva period (full line); 10-day larva-pupa transformation of the last larval instar (broken line), and 7-day pupa-adult interecdysial period (dotted line). B - starvation independent development and metamorphosis of the last larval instar. $\mathrm{C}-$ autonomic stimulation of development and metamorphosis induced in the headless body or isolated larval abdomens by removal of the whole cephalic neuroendocrine system (from Sláma, 1976; adapted).

of larval-pupal-adult transformation. The process proceeds step-by-step according to the inherited morphogenetic programme, which cannot deviate or pause until it arrives at the adult stage (Sláma, 1976). The regulation of metamorphosis without the intervention of PTTH and the moulting hormone fom the PG (Sláma et al., 1974) is mostly treated as a curiosity (Gilbert, 1989, 2009; Nijhout, 1994; Riddiford, 1996, 2008, 2012; Goodman \& Granger, 2005).

The essential features of the autonomic metamorphosis in D. vulpinus is schematically outlined in Fig. 14. The normal course of developent and metamorphosis are quite inconspicuous (Fig. 14A) and in many respects similar to the developmental schedule of Drosophila. In D. vulpinus the young larval instars grow very rapidly over a short period (3 days), the larval-pupal interecdysial period is much longer (10 days) and the pupal-adult instar lasts 7 days (Fig. 14A). Unlike in many other insects, starvation in the last larval instar does not inhibit the onset of metamorphosis. The pupae that form after starvation are somewhat smaller, but are able to develop into small adults that are capable of reproducing (Fig. 14B). The most peculiar features of development in D. vulpinus is illustrated in Fig. 14C, which shows that larvae deprived of the main hormonal centers (brain, CC, CA, PG) by removal of the head capsule, prematurely metamorphose into headless larvae, headless pupae and finally headless adults (Sláma, 1976; Delbecque
\& Sláma, 1980; review by Sláma et al., 1974). The spontaneous induction of metamorphosis by the removal of all essential parts of the neuroendocrine system (Fig. 14C) is a remarkable physiological feature, with many important physiological implications. Formation of a miniature pupa from the 3rd larval intar (ligatured 2nd instar larvae do not survive), shows that under these experimental conditions, almost a whole larval stage can be bypassed (Fig. 14C).

Perhaps the most intriguing physiological feature of autonomic metamorphosis in D. vulpinus is the spontaneous metamorphosis induced in isolated abdominal fragments, i.e. larval fragments develop into pupal and adult abdominal fragments, as depicted in Fig. 14C (Sláma, 1976). Moreover, the developing stages of $D$. vulpinus deprived of their neuroendocrine system plus PG, surprisingly show regular peaks in the concentration of endogenous ecdysteroid in the haemolymph (Delbecque \& Sláma, 1980), which indicates they were not produced by PG. Naturally, autonomic metamorphosis does not occur in the Lepidoptera, Galleria, Hyalophora and Manduca, because their larvae need several feed-back responses (spining of the cocoon, increase in temperature, long photoperiod), before the developmental schedule moves to the next stage (review by Sláma, 1985). On the other hand, the developmental scheme in Fig. 14 has several common features with that of Drosophila. In both species there are rapid 
larval-larval growth cycles, followed by relatively long periods of larval-pupal transformation (1.5 versus 5 days in Drosophila; 3 versus 10 days in Dermestes). In both instances, the short $(+\mathrm{JH})$ and long $(-\mathrm{JH})$ developmental periods never proceed simultaneously, $\mathrm{JH}$ treatment in the last larval instar never causes extra-larval moults or results in larval-pupal intermediates. These symptoms indicate the difficulties caused by not accepting that the hormonal control of metamorphosis in Drosophila (Riddiford, 2012) depends on autonomic development.

The antijuvenile mechanism, preventing the formation of larval-pupal intermediates, was the main obstacle to using juvenoids to control noxious coleopteran, dipteran and hymenopteran larvae (Sláma et al., 1974; Henrick, 1995), because the inborn antijuvenile mechanism prevent the juvenoids from killing last instar larvae of $D$. vulpinus (Sláma et al., 1974), Drosophila (Farkaš \& Polakovičová, 2013) and many other species (Sláma et al., 1974). The possibility of using juvenoids to induce supernumerary larval moults in Drosophila and other cyclorrhaphous flies (Calliphora, Sarcophaga) was investigated a long time ago by Žd'árek \& Sláma (1972). They revealed that the widespread acceptance of a genetically fixed 3 larval instars was not correct as it is possible to induce a supernumerary, 4th instar larvae not only by increasing JH-activity (as in D. vulpinus; Sláma, 1976), but also by injecting ecdysone within $5 \mathrm{~h}$ (in Drosophila) or 12 h (in Calliphora, Sarcophaga) of the 3rd larval ecdysis (Žd'árek \& Sláma, 1972).

\section{A unique series of several sucessive pupal instars}

It has been already mentioned that the selective developmental advantage of centrally produced hormones depends on the epigenetic transmission of essential environmental signals (favourable temperature, daylength, presence of food or water) to the subordinated genes in the peripheral target tissues and organs (Sláma, 2013). The signals are perceived by sense organs, carried by nerves to the brain and trasnsmitted via association neurones to the NSC. Here the nervous signals are transformed into chemical messengers, the neurohormones, which are sent to the neurohaemal organs (CC) and then released into the haemolymph. The circulating haemolymph distributes the hormonal messages from the central neuroendocrine system to its peripheral targets. In earlier sections it is explained that, when the environmental signals end, the process proceeds according to the predetermined morphogenetic schedule, in the absence of further intervention from the central neuroendocrine system. This hormone independent development was first documented in larvae of sawflies (Sláma, 1964c) and later in more detail in larvae of the carpet beetle D. vulpinus (Sláma, 1976).

Unfortunately, the developmental features of the autonomic regulation of insect metamorphosis is documented only by schematic diagrammes (Sláma, 1976). In order to show the actual morphological patterns depicted in Fig. $14 \mathrm{C}$ a unique series of headless pupal instars, produced by ligaturing 3rd to 6th instar larvae of $D$. vulpinus is presented in Fig. 15. This is similar to a series of small and large headless adults previously produced by decapitation

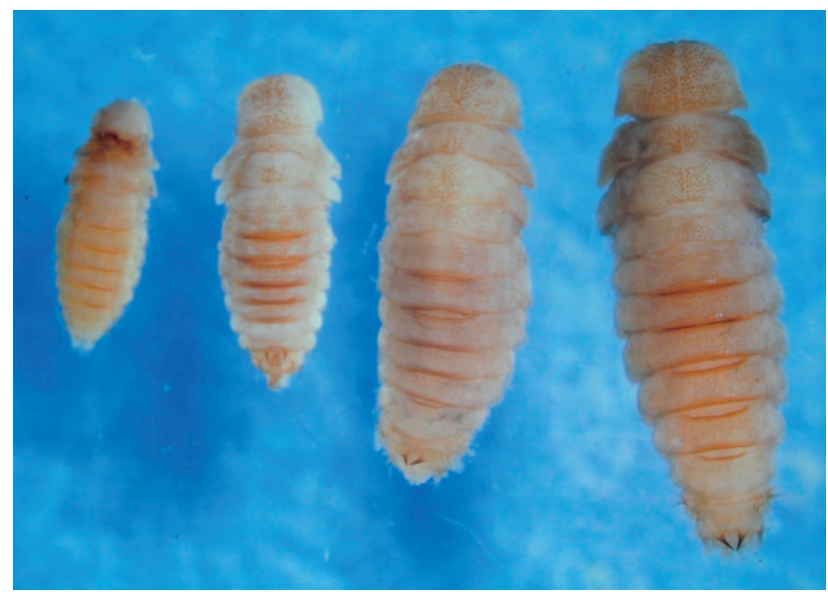

Fig. 15. Epidermal structures of headless prothetelic pupae obtained by ligaturing 3 rd to 6th instar larvae of $D$. vulpinus (see Fig. 14C). Distribution of the pupal epidermal tubercles on the tergites provides evidence of a constant rule in the displacement of potential pupal stem cells during successive larval instars.

of the young larval instars of Rhodnius (Wigglesworth, 1954, 1970). The pupae of D. vulpinus depicted in Fig. 15 have special pupal epidermal tubercles on their tergites. The spacial distribution of these tubercles on the pupae of different sizes indicates that there is a template for the distribution of these potentially pupal stem cells interspersed within the epidermis of previous larval instars. By way of illustration of the wide developmental capacity of $D$. vulpinus, the prematurely formed series of headless, prothetelic pupae in Fig. 15 is extended in Fig. 16 with the depiction of 2 nd and 3rd superumerary, metathetelic pupae, obtained by treating prepupae with $\mathrm{JH}$ analogues. Together, the 4 prothetelic and 2 metathetelic pupae (Figs 15 and 16) provide convincing evidence that the hormonal theory based on high, medium and low concentrations of JH (Piepho, 1951; Gilbert, 2009, 2012; Riddiford, 2012; Jindra et al., 2013) is incorrect.

Recent endocrinological studies are mostly based on the regulatory role of peripheral enzymes and genes and reverse the most important epigenetic endocrinological relationships. Introduction of the trivial enzymatic systems (esterase) or subordinated peripheral genes (Met, Kr-h1, Broad complex) are considered to override the action of centrally produced hormones (Konopová et al., 2011; Jindra et al., 2013; Smýkal et al., 2014a, b). The crucial philosophy of these modern studies is to support the tentatively anti-juvenile, precocious prothetelic properties of Met by poor, physiologically incompetent endocrinological evidence such as larval-pupal intermediates in Tribolium (Konopová \& Jindra, 2007), precociously moulting larvae in Bombyx (Smýkal et al., 2014a) and precocious adultoids in Pyrrhocoris (Smýkal et al., 2014b). Based on my experience of studying adultoids and allatectomized larvae (reviews by Sláma et al., 1974; Sláma, 1985, 1999) the evidence for the antijuvenile action of Met and RNAi injections in Tribolium (Konopová \& Jindra, 2007) is based on a false evaluation of trivial terratogenic effects. In addition, the tentatively antijuvnile effects of the Met gene in Pyr- 


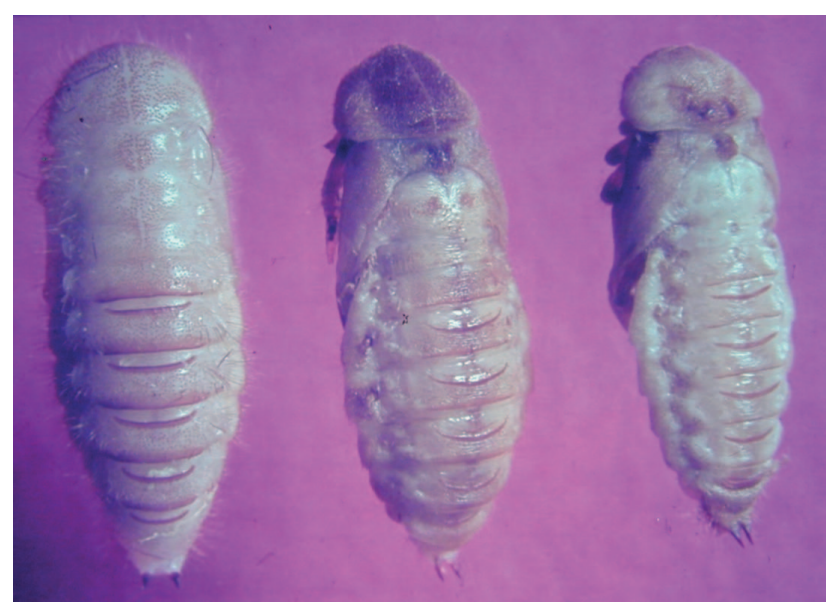

Fig. 16. A series of a normal (left) and 2nd and 3rd metathetelic supernumerary pupae of $D$. vulpinus, obtained by treatment of the prepupal stage with a juvenoid (from Sláma et al., 1974).

rhocoris (Jindra et al., 2013; Smýkal et al., 2014a, b) does not correspond with reality.

\section{Final considerations}

It is a mystery how incorrect hormonal theories (see Fig. 7) have survived unaltered five decades of endocrinological studies. Fifty-years ago there were no computers and scientific papers were typed, the preparation of drawings was laborious and endocrinologists devoted most of the time to practical work such as the extirpation and transplantation of endocrine glands (Pflugfelder, 1958; Sláma, 1962, 1964b, 1975; Novák, 1966). The most difficult endocrine gland to extirpate is the PG so it was often activated or deactivated, often decided on the basis of whether the thoracic fragment developed (Riddiford, 1985; Koolman, 1989; Nijhout, 1994; Riddiford et al., 2003; Klowden, 2007). PG was removed from hundreds of larvae of Galleria (Sláma, 1983) with no effect on the regular timing of moults. This indicates that PG has other physiological functions than the regulation of moults, which is generally ignored due to the widely used hormonal theory depicted in Fig. 7. By contrast, the inability of PG to stimulate moult cycles (Sláma, 1983) is seriously criticized and the results incorrectly rejected by Sehnal et al. (1988), who claimed that the PG-based theories of Piepho (1951), Schneiderman \& Gilbert (1964) and the original, brain-PG theory of Williams $(1947,1952)$ are correct because they are widely accepted. Sehnal et al. (1998) did not take into account that Williams abandoned his brain-PG theory (Williams, 1987) and claimed that Sláma (1983) was unable to remove the entire PG from a larval body. They report that a single PG cell remaining in Galleria can undergo hypertrophy and produce more Ecd than an entire PG (Sehnal et al., 1988). They did not know, however, that the PG, is a subordinated target of JH and unable to hypertrophy in last instar larvae of Galleria (Sláma, 1983; Sláma \& Lukáš, 2013).

During investigations of JH analogues, between 1965 and 1980, a large number of synthetic juvenoids were prepared and tested (Sláma, 1971, 1979, 1981, review by Sláma et al., 1974; Sehnal, 1982), of which 4000 were JH bioanalogues (Sláma, 1999), many of which were based on patent applications or unpublished protocols. The studies led to the discovery of a number of novel biologically important effects of $\mathrm{JH}$, like the "paper factor" effects on embryogenesis, "all-or-none" effects on individual cells, the sexual spread of insect sterility, systemic effets of juvenoids in plants, hormonal activity of peptidic JH analogues and many other JH effects (see reviews by Sláma, 1971, 1985, 1999, 2013; Sláma et al., 1974). This research was done in close cooperation with Zoecon Co., Palo Alto, Calif., USA. Unfortunately, the rewards, uncommon for the communist bloc, of bi-lateral American-Czechoslovak cooperation was suddenly discontinued in 1980 for political reasons. Since then, the research on JH analogues has greatly decreased (Wimmer \& Romaňuk, 1981; Sehnal, 1982, 1984; Sláma, 1985, 1999; Wimmer et al., 1997) and ambitious projects discontinued.

Currently there are no endocrinological studies using the old techniques. The peers of insect physiology have passed on and the 2nd and 3rd generation endocrinologists do not read old papers. They create new interpretations of insect hormone actions based on the modern state of molecular biology. For this reason, a 50-year old hormonal theory, good or wrong, persists as long as it is approved by anonymous reviewers. In the Czech Republic, the research on insect hormones has been continued by an ambitious team of young scientists (Konopová \& Jindra, 2007; Konopová et al., 2011; Jindra et al., 2013; Smýkal et al., 2014a, b). For theoretical reasons they use the hormonal theory of Gilbert-Riddiford (Fig. 7) that views the moulting hormone from the PG and JH-I as the true insect hormones. The epigenetic role of centrally produced hormones (Sláma, 1985, 2013) and the hormonal theory of Novák-Sláma are not considered to be important. The regulation of insect development is ascribed to peripheral genes and their receptors. In the paper by Konopová et al. (2011), for example, one can read that: "JH acts through its putative receptor Methoprene-tolerant (Met) to regulate Krüppel-homolog $1(\mathrm{Kr}-\mathrm{h} 1)$ and Broad Complex (Br-C) genes. While Met and $\mathrm{Kr}$-h1 prevent pecocious metamorphosis in pre-final larval instars, BR-C specifies the pupal stage...". It is remarkable how easily and elegantly modern molecular biologists solve a 50-year-old problem of insect hormone action. International team of modern authors (Smýkal et al., $2014 \mathrm{a}, \mathrm{b}$ ) believe that the sesquiterpenoid JH-I is the true JH of Pyrrhocoris, unaware of the fact that its JH activity is some 100,000 -fold smaller than that of a synthetic peptidic juvenoid (Sláma et al., 1964). I do not know how confident we can be with the biochemical conclusions, but, nevertheless, the precocious adultoids, which are the main argument for the existence of Met, are fictious.

Over the past 50-years several theories similar to the current Met theory have been proposed. Studying them is always costly in terms of money before they are quietly discontinued. Just to mention a few: (a) The delayed effects of JH from embryogenesis to metamorphosis; (b) The qualitative effects of high, medium and low concentrations of JH; (c) The lucrative claims that the isoprenoid JH-I is 
the true CA hormone; (d) Regulation of insect development by PTTH and PG; (e) Regulation of insect development by the enzymatic activity of JH esterase, and (f) The precocious induction of metamorphosis by manipulations of Met and Kr-1 genes (reviews by Sláma, 1999, 2013). In spite of the 4000 bioanalogues of $\mathrm{JH}$, the true nature of the hormone secreted by the insect corpus allatum still needs to be elucidated.

ACKNOWLEDGEMENTS. This work was presented as a lecture at the 10th International Conference on JH in Tsukuba, Japan, June 2014. The commitee of the conference headed by T. Shinoda refused to include this lecture in the proceedings of the conference (prepared for the Journal of Insect Physiology), because the interpretations put forward in this paper do not agree with generally accepted views.

\section{REFERENCES}

Antonova Y., Arik A.J., Moore W., Riehle M.A. \& Brown M.R. 2012: Insuline-like peptides: Structure, signaling and function. In Gilbert L.I. (ed.): Insect Endocrinology. Elsevier, Amsterdam, pp. 63-92.

BANNO Y. \& AKAI H. 1988: Ultrastructural changes of corpus allatum in the imaginal stages in the silkworm, Bombyx mori. $-J$. Seric. Sci. 57: 431-437.

BoDENSTEIN D. 1953: The role of hormones in molting and metamorphosis. In Roeder K.D. (ed.): Insect Physiology. John Wiley \& Sons, New York, pp. 879-931.

BounHIOL J.J. 1938: Recherches expérimentales sur le déterminisme de la métamorphose chez les Lépidoptères. - Bull. Biol. Fr. Belg. 24: 1-199.

Bowers W.S., Ohta T., Cleebe J.S. \& Marsella P.A. 1976: Discovery of insect antijuvenile hormones in plants. - Science 193: 542-547.

Cruickshank P.A. 1971: Some juvenile hormone analogues: A critical appraisal. - Mitt. Schweiz. Entomol. Gessellsch. 44: 97-114.

DelbecQue J.P. \& Sláma K. 1980: Ecdysteroid titres during autonomous metamorphosis in a dermestid beetle. - Z. Naturforsch. 35c: $1066-1080$.

Delbecque J.-P., Hirn M., Delachambre J. \& De RegGi M. 1978: Cuticular cycle and molting hormone levels during the metamorphosis of Tenebrio molitor (Insecta: Coleoptera). - Dev. Biol. 64: 11-30.

De Loof A., Boerjan B., Ernst U.R. \& Schoofs L. 2013: The mode of action of juvenile hormone and ecdysone: Towards an epi-endocrinological paradigm? - Gen. Comp. Endocrinol. 188: $35-45$.

De Loof A., De Haes W., Janssen T. \& Schoofs L. 2014: The essence of insect metamorphosis and aging: Electrical rewiring of cells driven by the principles of juvenile hormone-dependent $\mathrm{Ca}^{2+}$-homeostasis. — Gen. Comp. Endocrinol. 199: 70-85.

Devillers J. 2013a: Juvenile Hormones and Juvenoids. Modeling Biologial Effects and Environmental Fate. CRC Press, Boca Raton, 387 pp.

DevilLers J. 2013b: Juvenile hormones and juvenoids: A historical survey. In Devillers J. (ed.): Juvenile Hormones and Juvenoids. Modeling Biologial Effects and Environmental Fate. CRC Press, Boca Raton, pp. 1-14.

DeVILLERS J. 2013c: SAR and QSAR modeling of juvenile hormone mimics. In Devillers J. (ed.): Juvenile Hormones and Juvenoids. Modeling Biologial Effects and Environmental Fate. CRC Press, Boca Raton, pp. 145-174.
Dorn S., Frischknecht M.L., Martinez V., Zurflüh R. \& Fisher U. 1981: A novel non-neurotoxic insecticide with a broad activity spectrum. - Z. PflKrankh. PflSchutz 88: 269-275.

Engelman F. 1970: The Physiology of Insect Reproduction. Pergamon Press, Oxford, New York, 307 pp.

FARKAŠ R. \& PolakoviČOvÁ M. 2013: Using CoMFA and CoMSIA as tools in a 3D QSAR analysis of juvenile hormone agonist action in Drosophila. In Devillers J. (ed.): Juvenile Hormones and Juvenoids. Modeling Biologial Effects and Environmental Fate. CRC Press, Boca Raton, pp. 175-240.

Geary T.G. \& Maule A.G. 2010: Neuropeptide Systems as Targets for Parasite and Pest Control. Landes Bioscience and Springer Science and Business Media, Austin, New York, 250 pp.

GERSCH M. 1964: Vergleichende Endocrinologie der wirbellosen Tiere. Akademische Verlagsgesellschaft Geest und Portig, Leipzig, $170 \mathrm{pp}$.

GILBERT L.I. 1989: The endocrine control of molting: The tobacco hornworm, Manduca sexta as a model system. In Koolman J. (ed.): Ecdysone: From Chemistry to Mode of Action. Thieme Medical, New York, pp. 448-471.

GilBerT L.I. 2009: Insect Development: Morphogenesis, Molting and Metamorphosis. Academic Press, Elsevier, London, Burlington, San Diego, 739 pp.

GILBERT L.I. 2012: Insect Endocrinology. Elsevier, Amsterdam, $577 \mathrm{pp}$.

Gilbert L.I. \& Schneiderman H.A. 1958: The occurence of substances with juvenile hormone activity in adrenal cortex of vertebrates. - Science 128: 844.

Gilbert L.I. \& Schneiderman H.A. 1961: The content of juvenile hormone and lipid in Lepidoptera. - Compar. Endocrinol. 1: 453-472.

Goodman W. \& Cusson M. 2012: The juvenile hormones. In Gilbert L.I. (ed.): Insect Endocrinology. Elsevier, Amsterdam, pp. 310-365.

Goodman W. \& Granger N. 2005: The juvenile hormones. In Gilbert L.I., Iatrou K. \& Gill S.S. (eds): Comprehensive Molecular Insect Science. Vol. 3. Elsevier, Pergamon, Oxford, pp. 319-408.

HanC O. 1959: Hormone. Gustav Fischer, Jena, 633 pp.

Hanström B. 1939: Hormones in Invertebrates. Oxford University Press, London, Edinburgh, New York, Toronto, 198 pp.

HANSTRÖM B. 1953: Neurosecretory pathways in the head of crustaceans, insects and vertebrates. - Nature 171: 72-73.

HENRICK C.A. 1982: Juvenile hormone analogs: Structure-activity relationships. In Coates J.R. (ed.): Insecticide Mode of Action. Academic Press, New York, London, pp. 315-402.

Henrick C.A. 1995: Juvenoids. In Godfrey C.R.A. (ed.): Agrochemicals from Natural Products. Marcel Dekker, New York, pp. 147-213.

Highnam K.C. \& Hill L. 1969: The Comparative Endocrinology of the Invertebrates. Contemporary Biology. Edward Arnold, London, $270 \mathrm{pp}$.

Hodková M. 1976: Nervous inhibition of corpora allata by photoperiod in Pyrrhocoris apterus. - Nature 263: 521-523.

Hsiao T.H., Hsiao C. \& De Wilde J. 1975: Moulting hormone production in the isolated larval abdomen of the colorado beetle. - Nature 155: 727-728.

Hui J.H.L., Bendena W.G. \& Tobe S.S. 2013: Future perspectives for research on the biosynthesis of juvenile hormones and related sesquiterpenoids in Arthropod endocrinology and ecotoxicology. In Devillers J. (ed.): Juvenile Hormones and Juvenoids. Modeling Biologial Effects and Environmental Fate. CRC Press, Boca Raton, pp. 15-30. 
JANDA V. 1933: On the development and oxygen consumption of the isolated parts of the pupal body in Tenebrio molitor. - Acta Soc. Entomol. Čechoslov. 30: 1-14.

JedličKa P., CVAČKa J. \& SlÁma K. 2009: Juvenile hormonestimulated synthesis of acyl-glycerols and vitamin $\mathrm{E}$ in female accessory sexual glands of the fire bug, Pyrrhocoris apterus L. - Arch. Insect Biochem. Physiol. 72: 48-59.

JindRa M. 2014: Met/Gce is a bona fide JH receptor. In: Proceedings of 10th International Conference on Juvenile Hormones. National Institute of Agrobiological Sciences, Tsukuba, Plenary paper 5 .

JiNDRA M., PALli S.R. \& RidDiford L.M. 2013: The juvenile hormone signaling pathway in insect development. - Annu. Rev. Entomol. 58: 181-204.

Jizba J., Herout V. \& Sorm F. 1967: Polypodine B - a novel ecdysonlike substance from plant material. - Tetrahedron Lett. 51: 5139-5143.

KARLSON P. 1956: Biochemical studies on insect hormones. Vitam. Horm. 14: 227-266.

KARLSON P. 1966: Ecdyson, das Häutungshormon der Insekten. Naturwissenschaften 53: 445-453.

KARLSON P. 1971: Ecdysone, the prothoracic gland hormone of insects. In Novák V.J.A. \& Sláma K. (eds): Insect Endocrines. Academia, Praha, pp. 123-129.

Karlson P. \& Schmialek P. 1959: Nachweis der Excretion von Juvenilhormon. - Z. Naturforsch. 14: 832.

Karlson P. \& SeKeris E. 1966: Ecdysone, an insect steroid hormone and its mode of action. - Rec. Progr. Horm. Res. 22: 473-502.

Karrer F. \& FarooQ S. 1981: Some insect growth regulators with aromatic rings: Their synthesis and biological properties. In Sehnal F., Zabza A., Menn J.J. \& Cymborowski B. (eds): Regulation of Insect Development and Behaviour. Wroclaw Technical University Press, Wroclaw, pp. 289-302.

Klowden J. 2007: Physiological Systems in Insects. 2nd ed. Elsevier, Amsterdam, 688 pp.

Konopová B. \& JindRA M. 2007: Juvenile hormone resistance gene Methoprene-tolerant controls entry into metamorphosis in the beetle Tribolium castaneum. - Proc. Nat. Acad. Sci. USA 104: 10488-10493.

Konopová B., SmÝKal V. \& JindRa M. 2011: Common and distinct roles of juvenile hormone-signaling genes in metamorphosis of holometabolous and hemimetabolous insects. PLOS ONE 6: e8728.

Koolman J. 1989: Ecdysone: From Chemistry to Mode of Action. Thieme Medical Publishers, New York, 482 pp.

KoPEĆ S. 1922: Studies on the necessity of the brain for the inception of insect metamorphosis. - Biol. Bull. 42: 323-342.

Lafont R., Dauphin-Villemont C., Warren J.T. \& Rees H. 2012: Ecdysteroid chemistry and biology. Gilbert L.I. (ed.): Insect Endocrinology. Elsevier, Amsterdam, pp. 106-172.

LaW J.H., Yuan C. \& Williams C.M. 1966: Synthesis of a material with high juvenile hormone activity. — Proc. Nat. Acad. Sci. USA 55: 567-578.

Meyer A.S., Schneiderman H.A. \& Gilbert L.I. 1965: A highly purified preparation of juvenile hormone from the silk moth Hyalophora cecropia L. - Nature 206: 272-275.

Meyer A.S., Schneiderman H.A., Hanzmann E. \& Ko J.H. 1968: The two juvenile hormones from the Cecropia silk moth. Proc. Nat. Acad. Sci. USA 60: 853-860.

Murakoshi S., Nakata T., Ohtsuka Y., Akita H., Tahaba A. \& TAMURA S. 1975: Appearance of three-moulters from larvae of the silkworm, Bombyx mori L., by oral administration of abietic acid derivatives. - Jap. J. Appl. Entomol. Zool. 19: 267-272.
NÄSSEL D.R. 2002: Neuropeptides in the nervous system of Drosophila and other insects: multiple roles as neuromodulators and neurohormones. - Progr. Neurobiol. 68: 1-84.

Nation J.L. 2002: Insect Physiology and Biochemistry. CRC Press, Boca Raton, 485 pp.

Nishout H.F. 1994: Insect Hormones. Princeton Univ. Press, Princeton, NJ, $265 \mathrm{pp}$.

NovÁk V.J.A. 1959: Insektenhormone. 2nd ed. Czech Academy of Sciences, Prague, $283 \mathrm{pp}$.

NovÁk V.J.A. 1966: Insect Hormones. Methuen, London, 478 pp.

NovÁk V.J.A. 1967: The juvenile hormonme and the problem of animal morphogenesis. In Beament J.W. \& Treherne J.E. (eds): Insects and Physiology. Oliver \& Boyd, London, pp. 119-132.

NovÁk V.J.A. 1975: Insect Hormones. 2nd English ed. Chapman and Hall, London, 600 pp.

NovÁk V.J.A. 1991: Role of the gradient-factor in arthropod morphogenesis. In Gupta A.P. (ed.): Morphogenetic Hormones of Arthropods. Rutgers University Press, New Brunswick, NJ, pp. $3-43$.

NovÁK V.J.A. \& ČERVEnKovÁ E. 1960: The function of corpus allatum in the last larval instar of metabolic insects. In Hrdý I. (ed.): The Ontogeny of Insects. Czech Academy of Sciences, Prague, pp. 152-156.

NovÁK V.J.A. \& SlÁma K. 1960: On the question of origin of the pupal instar in insects. In Hrdý I. (ed.): The Ontogeny of Insects. Czech Academy of Sciences, Prague, pp. 65-69.

ParouleK M. \& Sláma K. 2014: Production of the sesquiterpenoid juvenile hormone (JH-I), and of vitamin E in the accessory sexual (colleterial) glands of adult male moths, Hyalophora cecropia (Linnaeus, 1758), (Lepidoptera: Saturniidae). — Life: The Excitements of Biology 2: 102-124.

Peter M.G., Gunawan S. \& Emmerich H. 1979: Preparation of optically pure juvenile hormone I labelled in the ester methyl group with tritium at very high specific activity. - Experientia 35: 1141-1142.

Peter M.G., Shirk P.D., Dahm K.H. \& Röller H. 1981: On the specificity of juvenile hormone biosynthesis in the male Cecropia moth. - Z. Naturforsch. 36c: 579-585.

Pflugfelder O. 1958: Entwicklungsphysiologie der Insekten. Akademische Verlagsgesellschaft Geest und Portig, Leipzig, $490 \mathrm{pp}$.

Piepho H. 1943: Wirkstoffe in der Metamorphose von Schmetterlingen und anderen Insekten. - Natuwissenschaften 31: 329-335.

PIEPHo H. 1951: Über die Lenkung der Insektenmetamorphose durch Hormone. — Verh. Dt. Zool. Ges. 1951: 62-76.

PodušKa K., HlaváčeK J., Šorm F. \& Sláma K. 1973: Simple peptide derivatives with insect juvenile hormone activity. In Nesvadba H. (ed.): Peptides. North Holland Publishing Company, Amsterdam, pp. 286-289.

RaABE M. 1982: Insect Neurohormones. Plenum Press, New York, $352 \mathrm{pp}$.

RIDDIFORD L.M. 1970: Prevention of metamorphosis by exposure of insect eggs to juvenile hormone analogues. - Science 167: 287-288.

RIDDIFORD L.M. 1985: Hormone action at the cellular level. In Kerkut G.A. \& Gilbert L.I. (eds): Comprehensive Insect Physiology, Biochemistry and Pharmacology. Vol. 8. Pergamon, Oxford, pp. 37-84.

RIDDIFORD L.M. 1996: Juvenile hormone: the status of its "status quo" action. - Arch. Insect Biochem. Physiol. 32: 271-286.

RIDDIFORD L.M. 2008: Juvenile hormone action. A 2007 perspective. - J. Insect Physiol. 59: 895-901. 
RIDDIFORD L.M. 2012: How does juvenile hormone control metamorphosis and reproduction? - Gen. Comp. Endocrinol. 179: 477-484.

Riddiford L.M., Hiruma K., Zhou X. \& Nelson C.K. 2003: Insights into the molecular basis of the hormone control of molting and metamorphosis from Manduca sexta and Drosophila melanogaster. - Insect Biochem. Mol. Biol. 33: 1327-1336.

RölLER H. \& BJERKE J.S. 1965: Purification and isolation of juvenile hormone and its action in lepidopteran larvae. - Life Sci. 4: 1617-1624.

RölLER H. \& DAHM K.H. 1970: The identity of juvenile hormone produced by corpora allata in vitro. - Naturwissenschaften 57: 454-455.

Röller H., Dahm K.H., Sweeley C.C. \& Trost B.M. 1967: Die Struktur des Juvenilhormons. — Angew. Chemie 79: 190-191.

Röller H., Bjerke J.S., Holthaus L.M., Norgard D.W. \& MCSHAN W.H. 1969: Isolation and biological properties of the juvenile hormone. - J. Insect Physiol. 15: 379-389.

Scharrer B. \& Scharrer E. 1937: Über Drüsennervenzellen und neurosekretorische Organe bei Wirbellosen und Wirbeltieren. - Biol. Rev. 12: 185-216.

Scharrer B. \& Scharrer E. 1944: Neurosecretion. VI. A comparison between the intercerebralis-cardiacum-allatum system of insects and the hypothalamo-hypophysial system of vertebrates. - Biol. Bull. 87: 242-251.

Schmialek P. 1961: Die Identifizierung zweier in Tenebriokot und in Hefe vorkommender Substanzen mit Juvenilhormonwirkung. - Z. Naturforsch. 16b: 461-464.

SCHMialeK P. 1963: Über die Bildung von Juvenilhormonen in Wildseidenspinnern. - Z. Naturforsch. 18b: 462-465.

Schneiderman H.A. \& Gilbert L.I. 1958: Substances with juvenile hormone activity in crustacea and other invertebrates. Biol. Bull. 115: 530-535.

Schneiderman H.A. \& Gilbert L.I. 1964: Control of growth and development in insects. - Science 143: 325-333.

Schneiderman H.A., Gilbert L.I. \& Weinstein M.J. 1960: Juvenile hormone activity in micro-organisms and plants. - Nature 188: $1041-1042$.

Schooley D.A., Horodyski M. \& CoAst G.M. 2012: Hormones controlling homeostasis in insects. In Gilbert L.I. (ed.): Insect Endocrinology. Elsevier, Amsterdam, pp. 366-429.

Schwarz M., Miller R.W., Wright J.E., Chamberlain W.F. \& Hopkins D.E. 1974: Compounds related to juvenile hormone. Exceptional activity of arylterpenoid compounds in four species of flies. - J. Econ. Entomol. 67: 598-601.

Sehnal F. 1982: Juvenile hormone analogues. In Downer R. \& Laufer H. (eds): Endocrinology of Insects. Alan R. Liss, New York, NY, pp. 657-672.

Sennal F. 1984: The juvenile hormone of insects. - Nova Acta Leopold. 56: 251-266.

Sehnal F., Fonágy A., Akai H. \& Kallenborn H.G. 1988: Prothoracic glands and ecdysteroid titre in Galleria mellonella larvae. - J. Insect Physiol. 34: 609-614.

Sehnal F., Švácha P. \& ZrZavÝ J. 1996: Evolution of insect metamorphosis. In Gilbert L.I., Tata J.R. \& Atkison B.G. (eds): Metamorphosis: Postembryonic Reprogramming of Gene Expression in Amphibian and Insect Cells. Academic Press, San Diego, CA, pp. 3-58.

ShiRK P.D., DAHM K.H. \& RÖlleR H. 1976: The accessory sex glands as the repository for juvenile hormones in male Cecropia moths. - Z. Naturforsch. 31c: 199-200.

ShiRK P.D., Bhaskaran G. \& Röller H. 1983: Developmental physiology of corpora allata and accessory sex glands in the Cecropia silkmoth. - J. Exp. Zool. 227: 69-79.
SlÁma K. 1961: Pseudo-juvenilizing effect in insects. - Acta Soc. Entomol. Čechoslov. 58: 117-120.

SLÁmA K. 1962: The juvenile hormone-like effect of fatty acids, fatty alcohols and some other compounds in insect metamorphosis. - Acta Soc. Entomol. Čechoslov. 59: 323-340.

SlÁmA K. 1964a: Die Einwirkung des Juvenilhormons auf die Epidermiszellen der Flügelanlagen bei künstlich beschleunigter und verzögerter Metamorphose von Pyrrhocoris apterus L. - Zool. Jb. Physiol. 70: 427-454.

SLÁMA K. 1964b: Hormonal control of respiratory metabolism during growth, reproduction and diapause in female adults of Pyrhocoris apterus L. (Hemiptera). - J. Insect Physiol. 10: 283-303.

SLÁmA K. 1964c: Physiology of sawfly metamorphosis. 2. Hormonal activity during diapause and development. - Acta Entomol. Bohemoslov. 61: 210-219.

SLÁMA K. 1965: Effect of hormones on the respiration of body fragments of adult Pyrrhocoris apterus L. (Hemiptera). Nature 205: 416-417.

SLÁMA K. 1971: Insect juvenile hormone analogues. - Annu. Rev. Biochem. 40: 1079-1102.

SlÁmA K. 1975: Some old concepts and new findings on hormonal control of insect morphogenesis. - J. Insect Physiol. 21: 921-955.

SLÁMA K. 1976: Old concepts and new findings on hormonal control of morphogenesis in Dermestes. - Coll. Int. C.N.R.S. 251: 499-506.

SLÁMA K. 1978: The principles of antihormone action in insects. - Acta Entomol. Bohemoslov. 75: 65-82.

SLÁmA K. 1979: Insect hormones and antihormones in plants. In Rosenthal G.A. \& Jansen D.H. (eds): Herbivores: Their Interaction with Secondary Plant Metabolites. Academic Press, New York, London, pp. 683-700.

SlÁMA K. 1980a: Homeostatic function of ecdysteroids in ecdysis and oviposition. - Acta Entomol. Bohemoslov. 77: 145-168.

SLÁmA K. 1980b: Animal hormones and antihormones in plants. - Biochem. Physiol. Pflanzen 175: 177-193.

Sláma K. 1981: Juvenoids in retrospect and juvenogens in prospect. - Sci. Pap. Wroclaw Techn. Univ. 22: 853-868.

SLÁMA K. 1982: Inverse relationships between ecdysteroid titres and total body metabolism in insects. - Z. Naturforsch. 37c: 839-844.

SlÁmA K. 1983: Illusive functions of the prothoracic gland in Galleria. - Acta Entomol. Bohemoslov. 80: 160-176.

SlÁMA K. 1985: Pharmacology of insect juvenile hormones. In Kerkut G.A. \& Gilbert L.I. (eds): Comprehensive Insect Physiology, Biochemistry and Pharmacology. Vol. 8. Pergamon, Oxford, pp. 357-394.

SlÁmA K. 1988: The mysterious thoracic hormonal centre in insects. In Sehnal F., Zabźa A. \& Denlinger D.L. (eds): Endocrinological Frontiers in Physiological Insect Ecology. Wroclaw Technical University Press, Wroclaw, pp. 663-675.

SlÁmA K. 1993: Ecdysteroids: insect hormones, plant defensive factors, or human medicine? - Phytoparasitica 21: 3-8.

SLÁMA K. 1995: The present status of the mode of action of insect juvenile hormone. - Neth. J. Zool. 45: 71-78.

SlÁma K. 1998: The prothoracic gland revisited. - Ann. Entomol. Soc. Am. 91: 168-174.

SLÁmA K. 1999: The history and current status of juvenoids. In Robinson W.M., Rettich F. \& Rambo G.W. (eds): Proceedings of 3rd International Conference on Urban Pests, July 19-22, 1999, Hronov, Czech Republic. Prague, pp. 9-25.

SLÁmA K. 2012: A new look at the comparative physiology of insect and human hearts. - J. Insect Physiol. 58: 1072-1081. 
SLÁMA K. 2013: Insect hormones: more than 50-years after discovery of insect juvenile hormone analogues (JHA, juvenoids). - Terrestr. Arthrop. Rev. 6: 1-77.

SLÁMA K. \& LAFONT R. 1995: Insect hormones - ecdysteroids: their presence and actions in vertebrates. - Eur. J. Entomol. 92: 355-377.

SLÁMA K. \& LuKÁŠ J. 2013: Role of juvenile hormone in the hypermetabolic production of water revealed by the $\mathrm{O}_{2}$ consumption and thermovision images of larvae of insects fed a diet of dry food. - Eur. J. Entomol. 110: 221-230.

Sláma K. \& Weyda F. 1997: The all-or-none rule in morphogenetic action of juvenile hormone on insect epidermal cells. Proc. R. Soc. Lond. (B) 264: 1463-1470.

Sláma K. \& Williams C.M. 1966a: The juvenile hormone V. The sensitivity of the bug, Pyrrhocoris apterus, to a hormonally active factor in American paper-pulp. - Biol. Bull. 130: 235-246.

SLÁmA K. \& Williams C.M. 1966b: "Paper factor" as an inhibitor of the embryonic development of the European bug, Pyrrhocoris apterus. - Nature 210: 329-330.

SlÁmA K., RomaňuK M. \& Šorm F. 1974: Insect Hormones and Bioanalogues. Springer, Wien, New York, 477 pp.

SmÝkal V., Daimon T., Kuyakawa T., Takashi K., Shinoda T. \& JINDRA M. 2014a: Importance of juvenile hormone signaling arises with competence of insect larvae to metamorphose. Dev. Biol. 390: 221-230.

Smýkal V., Bajgar A., Provazník J., Fexová S., Buřičová H., Takaki K., Hodková M., Jindra M. \& Doležel D. 2014b: Juvenile hormoe signaling during reproduction and development of the linden bug Pyrrhocoris apterus. - Insect Biochem. Mol. Biol. 45: 69-76.

Smith W. \& RybcZynski R. 2012: Prothoracicotropic hormone. In Gilbert L.I. (ed.): Insect Endocrinology. Elsevier, Amsterdam, pp. $1-62$.

TomBes A.S. 1970: An Introduction to Invertebrate Endocrinology. Academic Press, New York, London, 217 pp.

WigGLESWORTH V.B. 1935: Function of the corpus allatum in insects. - Nature 136: 338 .

WigGLESWORTH V.B. 1936: The function of the corpus allatum in the growth and reproduction of Rhodnius prolixus. - Quart. J. Microscop. Sci. 79: 91-119.

WigGLESWORTH V.B. 1940: The determination of characters at metamorphosis in Rhodnius prolixus. - J. Exp. Biol. 17: 201222.

Wigglesworth V.B. 1954: The Physiology of Insect Metamorphosis. Cambridge University Press, Cambridge, 152 pp.

Wigglesworth V.B. 1962: Endocrine regulation during development. I. Hormones in relation to metamorphosis. - Gen. Comp. Endocrinol. 1: 316-321.

WigGlesworth V.B. 1970: Insect Hormones. Oliver \& Boyd, Edinburgh, 159 pp.
Williams C.M. 1947: Physiology of insect diapause II. Interaction between the pupal brain and prothoracic glands in the metamorphosis in the giant silkworm, Platysamia cecropia. Biol. Bull. 93: 89-98.

WiLliams C.M. 1952: Physiology of insect diapause. IV. The brain and prothoracic glands as an endocrine system in the $\mathrm{Ce}$ cropia silkworm. - Biol. Bull. 103: 120-138.

WILLIAMS C.M. 1963: The juvenile hormone. III. Its accumulation and storage in the abdomens of certain male moths. - Biol. Bull. 124: 355-367.

WiLliams C.M. 1987: Midgut of lepidopteran pupae is a major depot of sequestered, mobilizable ecdysteroids. - Mem. Inst. Oswaldo Cruz 82: 47-49.

Williams C.M. \& Kafatos F.C. 1971: Theoretical aspects of the action of juvenile hormone. - Bull. Entomol. Soc. Suisse 44: 151-162.

WiLliams C.M. \& RobBins W.E. 1968: Conference on insect-plant interactions. - BioScience 18: 791-799.

Williams C.M., Moorhead L.V. \& Pulis J.F. 1959: Juvenile hormone in thymus, human placenta and other mammalian organs. - Nature 183: 405.

Willis J.H. 2007: Metamorphosis starts with Met. - Proc. Nat. Acas. Sci. USA 104: 10297-10298.

Willis J.H., Rezaur R. \& Sehnal F. 1982: Juvenoids cause some insects to form composite cuticles. - J. Embryol. Exp. Morphol. 71: 25-40.

WiLson T.G. \& FABIAN J. 1986: A Drosophila melanogaster mutant resistant to a chemical analog of juvenile hormone. - Dev. Biol. 118: 90-201.

Wimmer Z. \& RomañuK M. 1981: The syntheses of biologically active 2-(4-hydroxybenzyl)-1-cyclohexanone derivatives. Coll. Czech Chem. Commun. 46: 2573-2586.

Wimmer Z., Rejzek M., Zarevúcka M., Kuldová J., Hrdý I., NĚMEC V. \& ROMAŇUK M. 1997: A series of bicyclic insect juvenile hormone analogs of Czech origin: Twenty years of development. - J. Chem. Ecol. 23: 605-628.

YamanaKa N., Rewitz K.F. \& O'Connor M.B. 2013: Ecdysone control of developmental transitions: lessons from Drosophila research. - Annu. Rev. Entomol. 58: 497-516.

Yamashita Y., TANI K. \& KobaYASHI M. 1961: The effects of allatectomy on the number of eggs in the silkworm, Bombyx mori. - Acta Serol. 39: 12-15.

ŽĎÁREK J. \& SLÁMA K. 1972: Supernumerary larval instars in cyclorrhaphous Diptera. — Biol. Bull. 142: 350-357.

ŽITŇAN D. \& ADAMS M.E. 2012: Neuroendocrine regulation of ecdysis. In Gilbert L.I. (ed.): Insect Endocrinology. Elsevier, Amsterdam, pp. 253-309.

ŽitŇan D., Hollar L., Spalovská I., TakÁč P., ŽitŇanová I., Gill S.S. \& Adams M.E. 2002: Molecular cloning and function of ecdysis-triggering hormones in the silkworm Bombyx mori. J. Exp. Biol. 205: 3459-3473.

Received December 5, 2014; revised and accepted April 27, 2015 Prepublished online July 8, 2015 